\title{
Uma Estrutura Quase-Conjuntista Para a Mecânica QUÂNTICA NÃO-RELATIVISTA
}

\author{
JAISON SCHINAIDER
}

\begin{abstract}
In this article, we discuss some questions about the nature of elementary particles treated by quantum mechanics, in particular related to the concepts of identity and individuality of these particles. We started briefly exposing the philosophical and formal concepts of the identity and individuality, and then show how these notions are problematic when applied to elementary particles such as electrons, protons and neutrons. In particular, we emphasize that both philosophy, logic and set theory (and thus the mathematics) admit the usual assumption that things have a 'type' of identity and individuality (i.e., are individuals), in the sense that objects which have all the same properties are the same object (are equal). Nevertheless, we show that in the quantum universe is possible to find objects that share all their properties, but are not just one, constituting in something like "nonindividuals" (thesis defended by many physicists and philosophers of science). In sequence, we show how classical mathematics - which, as we said, assumes an individuality to your entities - handle this situation, in particular admitting assumptions external to the physical theories. To avoid this procedure, and look for a formalism more 'natural' and appropriate to work with these quantum characteristics, we suggest the use of a non-classical set theory called the quasi-set theory, based on a non-reflective logics, which admits objects devoid of identity and individuality $a b$ initio. Finally, we show another application of this theory: the search to a quasi-set mathematical structure that describes the 'behaviour' of non-relativistic quantum theory, and discuss some advantages of this 'quasi-structure' to a classical one.
\end{abstract}

Keywords: Quantum mechanics; identity; individuality; quasi-set theory; mathematical structures.

\section{Introdução}

Como é bem sabido, a Mecânica Quântica (MQ) trouxe à tona diversas questões intrigantes, tanto do ponto de vista físico bem como filosófico. Paradoxos como o famoso gato de Schrödinger, a existência de estados de superposição, a dualidade onda-partícula, o efeito de tunelamento - apenas para citar alguns exemplos — são fenômenos que nem de longe têm paralelo no chamado "mundo clássico". ${ }^{1}$ Por isso mesmo, tais eventos nos soam totalmente antintuitivos e estranhos à nossa usual concepção de realidade. Não obstante, há tempos sabemos que a nossa visão intuitiva do mundo que nos cerca não é um alicerce seguro para justificarmos nossas asserções: mesmo na física clássica, na chamada mecânica relativista, conclusões como a de que o tempo passa de modo diferente de acordo com o observador (ou mesmo de que o tempo em si é uma ilusão) ainda nos deixam atônitos. ${ }^{2}$

Principia 17(1): 103-135 (2013).

Published by NEL — Epistemology and Logic Research Group, Federal University of Santa Catarina (UFSC), Brazil. 
De toda forma, entre as várias questões levantadas pela MQ, ${ }^{3}$ nos interessa uma que muitas vezes não é em especial percebida pelos filósofos da ciência: a que se refere à questão da identidade e individualidade das entidades quânticas como elétrons, prótons e nêutrons, por exemplo. Como se sabe, em suas propriedades intrínsecas, os objetos quânticos - em cada classe - são todos 'iguais' (ou como preferimos afirmar, são todos indistinguíveis): elétrons, por exemplo, são todos caracterizados como tendo uma massa específica bem definida (a saber, 9, 1093829110 ${ }^{2}$ microgramas) e um certo spin (ou up ou down), de modo que objetos que não tenham essas propriedades não são elétrons (um múon, por exemplo, tem uma massa cerca de 207 vezes a massa do elétron). O mesmo acontece com as outras partículas elementares, ${ }^{4}$ de modo que soa um tanto estranho (e os físicos realmente não fazem isso) afirmar que duas partículas de um mesmo tipo sejam diferentes. Neste mesmo sentido, se tomarmos duas partículas indistinguíveis, e colocarmos uma à minha direita e outra à minha esquerda, depois de superpostas (que grosso modo poderia ser entendido como algo análogo à ação clássica de 'misturá-las') é impossível reidentificarmos tais partículas de modo a posteriormente afirmar que "esta partícula, seguramente, é a que antes estava à minha direita", por exemplo. O problema se mostra ainda mais perene quando tomamos os bósons ${ }^{5}$ em estados entangled, no qual não conseguimos nem mesmo atribuir propriedades individualizantes aos mesmos: nestes estados, tais partículas compartilham de todas as suas propriedades (incluindo as espaço-temporais), tornando-se, assim, absolutamente indistinguíveis. Dada tais características (entre muitas outras que poderiam ser citadas), desde os primórdios do desenvolvimento da teoria quântica alguns autores começaram a defender uma posição que depois ficou conhecida como concepção recebida da individualidade das partículas elementares: para tais pensadores, os entes quânticos seriam objetos que não possuiriam identidade (no sentido usual de "identidade" em matemática e filosofia, segundo o qual entidades idênticas são a mesma entidade), podendo assim ser entendidos como "não-indivíduos" (oposto assim à visão intuitiva de que um indivíduo é um objeto que sempre possui algo que o identifique propriamente). ${ }^{6}$ Roger Penrose, por exemplo, afirma claramente que "partículas diferentes [no sentido de não serem a mesma partícula] de um mesmo tipo não podem ter identidade" (Penrose 1989, p.294).

Uma questão que logo se coloca é como podemos então 'manipular' essa falta de identidade e individualidade em nosso formalismo. Isso se mostra essencial, haja vista que tal quadro acarreta situações um tanto difíceis de serem acomodadas no arcabouço teórico clássico. Por exemplo, a lógica subjacente às teorias físicas, por pressuposto, é a lógica clássica, que juntamente com a teoria de conjuntos clássica, alicerça as ferramentas matemáticas usuais que o cientista faz uso para construir suas teorias. ${ }^{7}$ Não obstante, em tais teorias formais, se tivermos duas entidades, então elas são necessariamente distintas, e o problema (como mencionamos rapi- 
damente acima) é que do ponto de vista físico tal distinção nem sempre é possível de ser apontada. A discussão se complica ainda mais a partir da constatação de que tal impossibilidade não é uma ignorância epistemológica da nossa parte: se caso aceitarmos que existe uma propriedade individualizadora que embora desconhecida poderia conferir uma diferença aos objetos quânticos - e entendermos essa propriedade como uma variável oculta, por exemplo - podemos ficar em apuros. Segundo alguns autores, assumir algum tipo de propriedade que, apesar de desconhecida, poderia conferir uma diferença aos objetos quânticos leva aos chamados "no-go theorems"; os quais declaram que uma particular situação não é fisicamente possível. Especificamente, tal termo descreve resultados (como o teorema de Bell e o de Kochen-Specker) que reprime os tipos possíveis de variáveis ocultas que podem fisicamente ocorrer, de modo que tudo leva a crer que realmente não há nenhuma outra propriedade para além das descritas pelas teorias físicas. ${ }^{8}$ Além disso, é praticamente um consenso que a $\mathrm{MQ}$ (em qualquer versão) não admite nenhum tipo de "substrato metafísico" para seus objetos: como dito, estes seriam exatamente a soma de seus atributos ou características prescritas pelas leis físicas que os governam (Redhead \& Teller 1991, 1992, Teller 1995). Deste modo, pelo que tudo indica, a questão aqui é ontológica, ou seja, estamos tratando com objetos que realmente não se coadunam com a forma como entendemos a identidade na lógica e matemática padrão por partilharem do mesmo quadro de características (sendo assim idênticos), mas não sendo um só.

Do ponto de vista estritamente filosófico, por sua vez, a questão também é um tanto complexa. Em geral, as teorias filosóficas da individualidade podem ser divididas em duas correntes principais. A primeira delas, e a qual é a mais intuitiva, é a chamada "Teoria dos Feixes" por tomar a individualidade de um objeto como sendo dada a partir do conjunto completo de propriedades ou atributos deste objeto. ${ }^{9}$ Como essa alternativa explica a individualidade dos objetos em termos das propriedades possuídas pelos mesmos, objetos que possuem propriedades distintas são indivíduos distintos. Veja que aqui a individualidade e a distinguibilidade colapsam em uma só noção: são indivíduos os distinguíveis por alguma propriedade (o que promove assim uma economia metafísica). De toda forma, uma das primeiras dificuldades que este tipo de posição filosófica deve enfrentar é o problema da instanciabilidade múltipla: ela necessita garantir que nenhuma outra entidade possa possuir o mesmo conjunto de propriedades, pois nesse caso poderíamos ter dois indivíduos com propriedades iguais, o que levaria essa abordagem à derrocada. Normalmente, para garantir que isso não seja possível, se apela para algum conjunto de propriedades que se imagina serem particulares apenas a algum objeto em questão, somado a algum outro princípio metafísico que assegure que nenhuma outra entidade possua tal conjunto de propriedades. Com relação às propriedades 'aceitas' para os objetos clássicos, podese invocar as chamadas espaço-temporais, e atrelar a tais objetos o chamado "Princí- 
pio da Impenetrabilidade" da física clássica: dois objetos não podem ocupar a mesma localização espaço-temporal, ao mesmo tempo, pois são impenetráveis. Com relação ao princípio metafísico requerido, por sua vez, normalmente se assume o chamado Princípio da Identidade dos Indiscerníveis (PII) de Leibniz, o qual insiste que não pode haver dois (ou mais) indivíduos com todas as propriedades iguais (incluindo então as espaço-temporais) sem serem o mesmo indivíduo. ${ }^{10}$ Desta forma, na proposta da identidade via feixes, dois indivíduos podem ser indistinguíveis em termos de suas propriedades intrínsecas (entendida aqui como sendo o conjunto de propriedades 'internas' do objeto), mas não em termos de suas propriedades espaço-temporais (se a impenetrabilidade for assumida).

Um outro princípio de individualidade possível é aquele que invoca algo "over and above" [para além] de algum conjunto de propriedades de uma entidade: uma "Individualidade Transcendental (TI)" Post 1963. Em resumo, a ideia é de que se assumirmos que possa haver dois objetos com todas as propriedades iguais (incluindo as espaço-temporais), e ainda quiséssemos nos referir a eles como indivíduos (ou seja, como tendo identidade), restaria a possibilidade de admitir que tal individualidade seja a eles atribuída por algo externo ao seu quadro de características ou propriedades, transcendendo assim tais atributos. Historicamente, vários 'candidatos' foram propostos para este "algo": na Idade Média um "haecceitas" (termo latino que poderia ser entendido como uma "essência individual" (Cross 2010)); mais atualmente, um "thisness primitivo", ou uma "unidade fundamental", ou - como fez Quinton 1973 p.24-5 — defini-lo como uma "substância". ${ }^{11}$ Não obstante, em todos a ideia permanece a mesma, a saber, de que se dispusermos desse algo (o qual, como dito, sendo subjacente a todas as propriedades materiais não poderia ser expresso em termos de tais propriedades) poderíamos conferir individualidade e identidade aos objetos mesmo quando indiscerníveis. Aqui, como se pode notar, individualidade e distinguibilidade são conceitos que permanecem distintos, sendo a distinguibilidade expressa em termos das propriedades dos objetos (onde objetos iguais seriam indistinguíveis), mas a individualidade destes objetos sendo dada por esse tipo de substrato metafísico que está para além das propriedades dos mesmos (e, assim, mesmo iguais estes objetos poderiam ser indivíduos distintos nesta acepção).

O grande problema é que ambos destes princípios filosóficos também parecem se tornar ineficazes, por assim dizer, para os objetos quânticos. Acima falamos rapidamente de partículas elementares (bósons) que podem partilhar de todas as suas propriedades (incluindo as espaço-temporais), bem como de autores que enfatizam a visão de que algo "over and above" às propriedades de tais entidades também não pode ser admitido, de modo que aqui tanto a teoria dos feixes, bem como a teoria transcendental da individualidade, respectivamente, se tornam abrogadas (abaixo mostraremos isso com mais detalhes). Desta feita, temos um quadro no qual os objetos quânticos parecem realmente não se conformar à nossa concepção de identidade 
e individualidade em todas as formas (ou seja, tanto do ponto de vista formal não 'obedecendo' à teoria da identidade da lógica e da matemática clássica — como também não se adequando as concepções filosóficas usuais de individualidade), de modo que a assunção já tida por alguns físicos do passado de que tais objetos são efetivamente não-indivíduos parece ser bastante sensata. Se aceitarmos isso, nos interessa então buscar um formalismo mais adequado para acomodá-los, aqui em especial usando uma lógica e uma teoria de conjuntos alternativa, onde a noção de não-indivíduo possa figurar apropriadamente. Isso porque já que as relações de identidade e diferença não fazem sentido para os entes quânticos, podemos facilmente defender a visão de que o uso da lógica com identidade (i.e., a lógica clássica) não é algo que seja efetivo, pois nesta lógica todos os objetos satisfazem as leis usuais da identidade e são assim indivíduos em toda a acepção da palavra. Isso pressuposto, um modo de obtermos um 'não-indivíduo' de um ponto de vista lógico é então assumir um formalismo não-clássico onde se tenha variáveis para as quais alguma das leis lógicas da identidade seja derrocada (em particular, como veremos, 'desrespeitaremos' a lei reflexiva da identidade que - falando informalmente - expressa a ideia de que "todo o objeto é igual a si mesmo"). Com relação à semântica, essa também tem que ser construída em um fundamento (uma teoria de conjuntos nãoclássica) onde essas ideias também se afigurem apropriadamente, e neste artigo utilizaremos a chamada teoria de quase-conjuntos que incorpora em seu formalismo tais 'exigências'. Como enfatizaremos, acreditamos que tais delimitações formais captem uma posição não-individualizadora já a partir das teorias matemáticas-base onde pode ser erigida a teoria quântica. Em seguida, construiremos uma estrutura quaseconjuntista onde poderemos fundamentar uma axiomática para a MQ na qual esses não-indivíduos possam figurar $a b$ initio, e, por fim, discutiremos algumas vantagens desta abordagem frente à concepção clássica; em particular, a visão de que esta proposta assume de um modo mais 'natural' as características físicas (e metafísicas) das partículas elementares. Não obstante, primeiramente mostraremos em que sentido podemos realmente defender que os objetos quânticos são 'entidades sem identidade'.

\section{Individualidade e identidade na mecânica quântica}

Tal como vimos, a indistinguibilidade é uma noção que se refere a uma relação que existe entre coisas que partilham de propriedades ou atributos, e deve envolver assim mais que um objeto. A partir disso, é possível fazer uma distinção conceitual entre distinguibilidade e individualidade; esta última entendida como algo que pertence somente ao objeto em si. Em geral, nas discussões sobre partículas indistinguíveis, normalmente se limita as propriedades a serem assumidas de modo a se conside-

Principia 17(1): 103-135 (2013). 
rar apenas as chamadas intrínsecas, ou seja, as que são independentes de estado. ${ }^{12}$ Neste caso, mesmo partículas clássicas (isto é, aquelas descritas pela física clássica) podem ser indistinguíveis: um dos exemplos mais famosos neste sentido é o das chamadas "esferas de Black" (Black 1952), onde se imagina um universo contendo apenas duas esferas metálicas perfeitamente semelhantes, cada uma a uma milha de distância da outra. Aqui, alega-se, não obstante o fato de termos uma diversidade numérica das duas esferas, não há nenhuma propriedade intrínseca que se possa utilizar para distinguí-las. ${ }^{13}$ Todavia, a questão é que na física clássica essa (possível) indistinguibilidade não afeta o status de indivíduo de tais partículas, algo que como enfatizamos acima é diferente para o caso quântico. Para se mostrar o porque dessa diferença de posições, normalmente se lança mão da análise do comportamento estatístico de um conjunto de objetos (em geral, a distribuição de certas partículas em certos estados possíveis) tanto no caso clássico bem como caso quântico. Vamos ver como isso acontece, o que nos dará um melhor entendimento sobre o papel atribuído às noções de indistinguibilidade e de identidade na MQ.

Sendo assim, consideremos primeiramente o caso clássico, tomando a distribuição de duas partículas 1 e 2 do mesmo tipo — as duas esferas de Black, por exemplo - sobre duas caixas ou estados de energia $A$ e $B$. Como dito, tais partículas possuem as mesmas propriedades intrínsecas, tais como massa em repouso, forma etc., e no sentido que discutimos anteriormente elas seriam então indistinguíveis. Não obstante, no contexto da física clássica, assume-se que podemos gerar os seguintes arranjos para a distribuição das duas partículas indistinguíveis nos dois estados de energia $A$ e $B$ :

1) temos $1 / 4$ de chance de encontrar as duas partículas no estado $A$;

2) $1 / 4$ de encontrar as duas partículas no estado $B$;

3) $1 / 4$ de encontrar a partícula 1 em $A$ e a partícula 2 em $B$; e

4) $1 / 4$ de encontrar a partícula 1 em $A$ e a partícula 2 em $B$.

Esta probabilidade caracteriza as chamadas estatísticas de Maxwell-Boltzmann, e o que importa para nossa discussão advém dos casos 3) e 4) acima. Nestas duas ocorrências - dado que não podemos lançar mão da distinguibilidade das partículas, pois elas são indistinguíveis - termos duas atribuições de probabilidade advém exatamente de fato de estarmos tomando tais partículas como indivíduos de alguma forma, já que em seu comportamento coletivo a permutação promove uma diferença na contagem (isto é, a troca de uma partícula indistinguível por outra promove uma nova estatística). Dito de outro modo, como as situações 3) e 4) acima são consideradas situações físicas distintas, podemos considerar os objetos físicos em questão como distintos também, e assim, apesar de indistinguíveis, eles podem ser tomados como indivíduos na acepção plena da palavra, inclusive sendo possível nomeá-los 
(por exemplo, como ' 1 ' e '2' da forma que fizemos); ato que em princípio serve para identificá-los em outras situações. Os objetos que nos cercam em nossa escala macroscópica, por respeitarem a física clássica, também têm todos essas mesmas características, e é por isso que os chamamos de indivíduos.

Como essa individualidade deve ser entendida depende da teoria que aceitamos. De um modo mais simples, como vimos, a mecânica clássica (entendendo por isso a física newtoniana, a teoria eletromagnética de Maxwell, e a relatividade especial e geral) admite o princípio de impenetrabilidade. Neste caso, ainda que possam ter todas as mesmas características como marcas e arranhões (no caso dos objetos macroscópicos), ou o mesmo estado (no caso dos microscópicos), poderíamos lançar mão da teoria dos feixes e afirmar que tais objetos seriam indivíduos distintos em função de ocuparem posições espaço-temporais distintas. Não obstante, se não quiséssemos assumir propriedades espaço-temporais por elas não serem intrínsecas aos objetos, mesmo assim poderíamos também delinear uma alternativa combinatória que não levasse em conta explicitamente tais considerações: neste caso, como vimos, devemos incorporar algum tipo de individualidade transcendental aos objetos do sistema. De toda forma, o que importa ressaltar é que na física clássica, em princípio, sempre se pode dotar os objetos de individualidade (mesmo quando estamos tratando de objetos microscópicos), de modo que qualquer impossibilidade de individualidade aqui é entendida apenas como uma incapacidade epistemológica (e não ontológica) da nossa parte. ${ }^{14}$

No caso quântico, tal qual o caso clássico, o exame do impacto da física moderna sobre a filosofia da individualidade também perpassa o modo de distribuição de partículas indistinguíveis sobre certos estados, sendo assumido que cada resultado/arranjo tem uma certa probabilidade. Todavia, no caso da Mecânica Quântica em especial, temos partículas que se comportam de duas formas diferentes: as chamadas partículas 'tipo' Bose-Einstein [B-E] tem spin inteiro (como por exemplo os nêutrons e os prótons), e as chamadas partículas 'tipo' Fermi-Dirac [F-D] tem spin $1 / 2$ (como por exemplo os elétrons). A diferença básica é que dois ou mais bósons com todas as mesmas propriedades (incluindo as espaço-temporais) podem compartilhar um mesmo estado bosônico, enquanto que duas partículas fermiônicas (por respeitarem o Princípio da Exclusão de Pauli) não podem compartilhar um mesmo estado. Dado isso, de acordo com as partículas envolvidas, temos então dois tipos diferentes de estatísticas que as permitem distribuí-las nos dois estados $A$ e $B$, por exemplo. Entre outras coisas, tal distribuição é um dos principais motivos que fortalece a conclusão de que esses objetos podem ser entendidos como não-indivíduos de alguma forma.

Passaremos a utilizar a noção de Dirac para os estados quânticos, onde $|\psi\rangle$ representa um vetor $\psi$ qualquer em um espaço de Hilbert. Se as partículas forem bósons, eis os diferentes modos em que podemos distribuí-las via estatística B-E:

Principia 17(1): 103-135 (2013). 
5) partículas 1 e 2 estão no estado $\left|a^{1}\right\rangle$;

6) partículas 1 e 2 estão no estado $\left|a^{2}\right\rangle$;

7) uma partícula esta no estado $\left|a^{1}\right\rangle$ e uma partícula esta no estado $\left|a^{2}\right\rangle$.

Aqui, se assumirmos como se faz usualmente de que cada uma das distribuições é equiprovável, teremos que para os bósons cada um dos casos 5) a 7) tem a probabilidade 1/3 de ocorrer. Em 7), o fato de não estipularmos qual partícula (a 1 ou a 2) está em qual estado, simboliza precisamente o fato de que aqui as permutações das partículas não geram estados diferentes (divergindo assim do resultado encontrado nas estatísticas clássicas). Para os férmions, por sua vez, por obedecerem ao princípio de exclusão de Pauli, apenas 7) é um estado possível, o qual terá assim probabilidade 1 de ocorrer (o estado 7 acima representa assim exatamente a estatística Fermi-Dirac). Logo, para os férmions, a permutação das partículas também não gera um estado diferente, o que é exatamente expresso pela estatística F-D.

O próximo passo é vermos como podemos representar essas situações no formalismo da mecânica quântica ortodoxa. Como temos duas partículas indistinguíveis, vamos utilizar o mesmo espaço de Hilbert $H$ associado a ambas e descrever seus estados através do produto tensorial $\otimes$ desse espaço consigo mesmo:

5') $\left|a_{1}^{1}\right\rangle \otimes\left|a_{2}^{1}\right\rangle$

6) $\left|a_{1}^{2}\right\rangle \otimes\left|a_{2}^{2}\right\rangle$

7') $\frac{1}{\sqrt{2}}\left(\left|a_{1}^{1}\right\rangle \otimes\left|a_{2}^{2}\right\rangle+\left|a_{2}^{1}\right\rangle \otimes\left|a_{1}^{2}\right\rangle\right)$

8) $\frac{1}{\sqrt{2}}\left(\left|a_{1}^{1}\right\rangle \otimes\left|a_{2}^{2}\right\rangle-\left|a_{2}^{1}\right\rangle \otimes\left|a_{1}^{2}\right\rangle\right)$

Onde em 7') e 8'), $\frac{1}{\sqrt{2}}$ é uma constante de normalização, e toma-se 7') quando tratamos de bósons (utilizando-se para tanto vetores de estado chamados de simétricos: com o sinal + ), e $8^{\prime}$ ) quando tratamos de férmions (utilizando-se vetores chamados de assimétricos: com o sinal -). Utilizando-se as expressões 7') e 8'), representamos assim no nosso formalismo o fato de termos uma partícula em cada estado, sem importar qual partícula (no sentido da identidade) está em cada estado e sem que a permutação dos estados crie uma diferença na contagem (i. e., na estatística). Segundo alguns pensadores, esta característica de não importar qual partícula está em cada estado - já que diferentemente da estatística clássica uma permutação entre elas não gera uma diferença no sistema final — é um dos mais fortes argumentos à favor da visão de que as mesmas deveriam ser entendidas como não possuindo identidade, tornando-se assim não-indivíduos de algum tipo (obviamente, assumindo a posição bastante usual de que um indivíduo deve possuir identidade).

Do ponto de vista experimental, o fato de que a permutação de partículas não gera um novo arranjo é explicado em termos de que não existe medida que pode 
ser feita e que possa resultar em alguma diferença discernível entre o resultado permutado final, e o resultado não permutado inicial. O problema é que o produto tensorial no qual os dois estados acima são descritos não é comutativo, isto é, se tivermos um espaço de Hilbert $H_{\text {total }}=H_{1} \otimes H_{2}$, isto é diferente de $H_{\text {total }}=H_{2} \otimes H_{1}$. Isto quer dizer que no caso 7'), por exemplo,

$$
\frac{1}{\sqrt{2}}\left(\left|a_{1}^{1}\right\rangle \otimes\left|a_{2}^{2}\right\rangle+\left|a_{2}^{1}\right\rangle \otimes\left|a_{1}^{2}\right\rangle\right)
$$

é diferente de

$$
\frac{1}{\sqrt{2}}\left(\left|a_{2}^{2}\right\rangle \otimes\left|a_{1}^{1}\right\rangle+\left|a_{1}^{2}\right\rangle \otimes\left|a_{2}^{1}\right\rangle\right),
$$

o que é exatamente contrário ao que pretendemos, a saber, que a permutação dos estados gere o mesmo estado final tal qual o estado não permutado. Para garantir tecnicamente que o produto tensorial dos espaços de Hilbert onde são expressos os estados quânticos sejam comutativos, temos que assumir no nosso formalismo um postulado adicional externo à nossa teoria: o chamado Postulado da Indistinguibilidade (IP). Tal postulado basicamente 'impõe' na matemática clássica a característica física que encontramos, qual seja, a de que se uma permutação de partículas for impingida sobre um conjunto de partículas indistinguíveis, então não existe nenhum modo de distinguir o vetor permutado resultante do vetor original não permutado por meio da observação de tais partículas a qualquer momento (isto é, qualquer permutação não pode ser "observável": dar origem à situações físicas distintas). De modo mais formal, tal postulado diz que o valor esperado (esperança matemática) da medida de um observável qualquer ô para um sistema num estado $\psi$ é o mesmo antes e depois de qualquer permutação entre partículas indiscerníveis que formem o sistema. Usualmente, tal postulado pode ser representado por insistir que os operadores $\hat{O}$ que representam observáveis, quando aplicados aos vetores de estado, devem sempre comutar com os operadores de permutação $\hat{P}$, tal que para todo operador de permutação $\hat{P}$ : $[\hat{O}, \hat{P}]=0, \forall \hat{O} \forall \hat{P}$.

Consoante com as estatísticas quânticas, a assunção do IP também parece nos levar a negar a concepção de que as partículas quânticas sejam indivíduos que possam ser 'rotulados': do ponto de vista das estatísticas, os rótulos $\left|a_{y}^{x}\right\rangle$ das partículas do caso 7'), por exemplo, são ociosos, já que tais rótulos apenas estão mostrando que as partículas partilham de ambos os estados e que se trocarmos os estados isto não resulta em diferença alguma. Com efeito, o IP está no centro das discussões sobre a não-individualidade das partículas quânticas, e conforme apresentamos ele parece implicar que nada pode distinguir as partículas em questão. Compatível com a nossa posição, como discutimos anteriormente, diz que as partículas clássicas são indivíduos, mas que as partículas quânticas não são (cf. French \& Krause 2006 p.134-46).

Principia 17(1): 103-135 (2013). 
Muito bem, mas o problema é que esta 'saída' (que Redhead \& Teller 1991, 1992, Teller 1995 chamam de "Labeled-Tensor-Product-Hilbert-Space-Formalism") requer que pelo menos em certo sentido comecemos com indivíduos, "já que usando a matemática clássica [e a nossa linguagem usual] é impossível formular uma descrição dos estados que envolvam a indistinguibilidade desde o início" Schiller 2009 p.1056, por escolher um vetor de base rotulado como $\left|\alpha_{i}\right\rangle$ para cada espaço de Hilbert e assim para cada partícula. Embora este rótulo já sirva como um tipo de identificador para as partículas, como está em questão exatamente a impossibilidade deste próprio mecanismo de referência através de nomeação e rotulação, em sequência definimos (ou melhor dizendo, assumimos a partir do IP) que a permutação desses vetores não modifica o estado final do sistema e que podemos 'esquecer' tais rótulos, i.e., esquecer que estes vetores representam indivíduos que foram inicialmente rotulados e individualizados, podendo assim dizer que agora não é mais possível falar qual rótulo pertence a qual partícula. Como dissemos, todo esse 'malabarismo formal' é necessário porque a matemática clássica assume o PII como um dos seus pressupostos fundamentais, tornando-se assim atrelada à noção usual de individualidade na qual coisas iguais (aqui entendendo o partilhamento de todas as propriedades) são a mesma - uma só — coisa. ${ }^{15}$ Não obstante, do ponto de vista filosófico, isto se torna um pouco estranho: começamos assumindo uma diferenciação para os objetos e, posteriormente, aplicamos um postulado 'externo' à teoria e dizemos que eles não se diferenciam de modo algum. Deste modo, para a nossa discussão, importa ressaltar exatamente esse 'procedimento', a saber, o fato de que para se conseguir que na matemática padrão a permutação de estados não gere um novo estado temos que assumir coisas ad hoc, por assim dizer. Como enfatizado, todo esse modo de proceder somente 'mascara' o problema de não conseguirmos expressar tal nãoindividualidade já de um modo incipiente na teoria matemática fundamental: como disse Schrödinger, estamos a "entrar com o pé esquerdo"16 (além de que, como estamos tentando mostrar, mesmo com tal atitude a distinção feita por necessidade da linguagem permanece presente nos bastidores, estando apenas velada). Todavia, não há como resolver tal imbróglio exceto de estivermos dispostos a mudar radicalmente a base lógica e matemática da teoria quântica para uma que comporte, desde o princípio, algo como não-indivíduos. Como já discutimos na introdução, acreditamos que podemos 'entrar com o pé direito' se usarmos como fundamento básico da nossa ciência uma teoria de conjuntos alternativa chamada de teoria dos quase-conjuntos que, como veremos em sequência, no mínimo fornece uma abordagem muito mais 'honesta' a este problema.

\subsection{PII e individualidade quântica}

Caso o leitor ainda não tenha se convencido da falta de identidade e, do modo que estamos defendendo, individualidade das partículas quânticas a partir do exposto 
acima, mesmo assim poderíamos levantar várias outras objeções que permitem fortalecer a ideia de que tais objetos destoam do que entendemos como indivíduos do mundo usual, objeções essas que por sua vez não fazem uso da tal 'permutabilidade quântica'. Sendo assim, antes de mostrarmos o formalismo da teoria de quaseconjuntos, apenas para terminar esta seção exploraremos rapidamente mais algumas facetas da MQ que nos permitem sustentar a tese de que a assunção de qualquer tipo de "propriedade individualizante" falha nesse contexto, fazendo com que o PII - e assim a teoria dos feixes - acabem se tornando nulas nessa discussão. ${ }^{17}$

Como enfatizamos, o PII é satisfeito no contexto clássico porque a descrição do estado dinâmico gera uma bem definida e unicamente determinada trajetória espaçotemporal para cada partícula. Esta descrição invoca o Princípio da Impenetrabilidade (IA) e, assim, a distinção via localização espaço-temporal é assegurada. Com relação à MQ, já podemos afirmar que neste caso o PII é falso a partir do argumento que sobre a interpretação padrão, trajetórias espaço temporais únicas para as partículas em geral não existem French \& Krause 2006 seção 3.6.

Analisemos agora com mais detalhes os estados 7') e 8') acima, onde temos uma partícula em cada estado. Poderíamos afirmar que nesses casos o PII é satisfeito pois temos apenas uma partícula em cada estado separadamente. Para o caso dos férmions, inclusive, poderíamos afirmar ainda que realmente existe uma propriedade individualizante: a partir do chamado princípio da exclusão de Pauli, podemos assumir o PII como válido porque tais partículas respeitariam tal forma 'quântica' de IA.

Mas esta tentativa de salvar o PII para os elementos da MQ nas estatística 7') e 8') assumindo tal 'IA quântico' não é efetiva. Recordamos primeiramente o caso 8'), o qual é expresso formalmente do seguinte modo:

8') $\frac{1}{\sqrt{2}}\left(\left|a_{1}^{1}\right\rangle \otimes\left|a_{2}^{2}\right\rangle-\left|a_{2}^{1}\right\rangle \otimes\left|a_{1}^{2}\right\rangle\right)$.

Se considerarmos o estado anti-simétrico dado por tal descrição (que incorpora formalmente o princípio da exclusão via a antissimetrização), não é verdade que cada partícula esteja em um estado diferente. Na realidade, cada partícula compartilha de ambos os estados $|a 1\rangle$ e $|a 2\rangle$ na superposição do produto de estados expresso em $8^{\prime}$ ). Tais estados são chamados de estados "entangled"; os quais não podem ser separados (ou, dito de outra forma, não podem ser designados para partículas separadas, pois a função não é fatorável, o que nos permitiria obter cada uma das parcelas isoladamente), fazendo com que as partículas pertençam a ambos os estados $\left|a^{1}\right\rangle$ e $\left|a^{2}\right\rangle$ ao mesmo tempo e que também compartilhem, ao mesmo tempo, das mesmas propriedades estado-dependentes. O que temos assim é o sistema conjunto descrito pela função $\psi$, e ela simplesmente nos diz que temos uma partícula no estado $A$ e outra no estado $B$, mas jamais poderemos saber qual é qual (da Costa et. al. 2012). Por fim, é possível também provar que dois férmions em um estado entangled, por exemplo, têm as mesmas propriedades monádicas e relacionais um em relação ao outro French \& Krause

Principia 17(1): 103-135 (2013). 
2006 p.156. Isto tudo significa que se pensarmos nesses estados como representando as propriedades relevantes das partículas, o PII acaba sendo violado até mesmo para férmions que 'respeitam' o Princípio da Exclusão (o mesmo valendo para os bósons em 7'), para os quais até mesmo nem vale o Princípio de Exclusão). Além disso, vale citar que a existência dos estados entangled nos quais não podemos saber qual partícula é qual, por assim dizer, mostra uma característica efetivamente ontológica da natureza (e não uma incapacidade epistemológica, como no caso clássico antes citado), a ponto de Dalla Chiara \& Toraldo di Francia 1993 enfatizarem que nem mesmo uma mente onisciente - "nem mesmo em in mente Dei" — poderíamos definir uma função-denotação para os objetos quânticos de modo a poder nomeá-los e identificá-los nessas situações. Como dissemos acima, tais estados entangled representam um quadro claro onde se mostra uma impossibilidade de atrelarmos a tais objetos alguma teoria de feixes a partir de alguma propriedade individualizante: novamente, não-indivíduos.

Vamos considerar agora os casos 5' e 6' (lembrando, ambas as partículas estão no estado $\left|a^{1}\right\rangle$ ou ambas em $\left|a^{2}\right\rangle$ ) que valem apenas para bósons. Aqui, temos uma violação definitiva do PII "desde que a correspondente simetria da função de onda significa que dois ou mais bósons podem possuir todas as mesmas propriedades estado-dependentes e assim serem [plenamente] indistinguíveis " (French \& Krause 2006 p.150, grifo meu). Em resumo, como mostra a estatística, isso quer dizer que mais de um bóson pode ocupar o mesmo estado e compartilhar de todas as suas propriedades, levando a uma falha do (equivalente em MQ) princípio da impenetrabilidade. Além disso, as trajetórias espaço-temporais dos bósons não podem servir para individualizá-los. Tome por exemplo dois fótons: nos pontos em que suas trajetórias se cruzam e os fótons compartilham todas as suas propriedades espaço temporais em comum, torna-se logicamente impossível determinar qual fóton em cada ponto tem cada história. O mesmo acontece quando temos uma colisão entre duas partículas deste tipo: seria necessário seguir o caminho do movimento de cada uma, "mas não temos nenhuma chance de conseguir isso" (Schiller 2009, p.10534) porque o erro da leitura da posição da partícula é maior do que o tamanho da partícula em si. Experiências mostram ainda que em pequenas distâncias é impossível dizer se tais partículas mudaram sua direção ou não, e essa impossibilidade é uma consequência direta do quantum de ação (ibid.). Com efeito, nenhuma experiência pode rastrear partículas com propriedade intrínsecas idênticas de tal modo que elas possam ser distinguidas com certeza (Wick 1996, cap.5). Esta impossibilidade foi verificada experimentalmente com todas as partículas elementares, com núcleos, com átomos, e com numerosas moléculas (Schiller 2009 p.1058). Aqui vemos que a alternativa clássica de tanto individualizar como distinguir as partículas em termos de sua localização espaço-temporal padece de várias dificuldades, de modo que muitas características intuitivas que temos para dotar um objeto de individualidade

Principia 17(1): 103-135 (2013). 
(como poder segui-lo o tempo todo - isto é, possuir continuidade espaço-temporal tendo assim uma trajetória determinada —, poder rotulá-lo, reidentificá-lo em outras situações etc.) acabam sendo frustradas (cf. Uffink \& Hilgevoord 1988). ${ }^{18}$ Deste modo, a abordagem do problema da individualidade segundo uma teoria de feixes de propriedades parece ser completamente descartada também para os bósons. ${ }^{19}$

Vários argumentos extras ainda poderiam nos auxiliar na defesa de uma posição 'não-individualizadora' para as partículas quânticas. Não obstante, essa discussão não é completamente nova e não passou despercebida durante o desenvolvimento dessa disciplina. Como dissemos na introdução, vários autores (Heisenberg, Weyl, Born, Schrödinger, entre outros French \& Krause 2006) defenderam a visão de que de que os objetos quânticos não poderiam mais ser identificados de forma alguma, e que teriam por isso perdido sua individualidade (desta forma, em certo sentido, se tornando não-indivíduos tal como estamos defendendo). Entre estes, vamos apenas citar aqui a posição de Erwin Schrödinger. Em seu What is an elementary particle? (1957), por exemplo, este autor explicitamente sustenta a posição de que o conceito de identidade realmente carece de sentido para as partículas elementares - $\mathrm{o}$ mesmo se dando para a questão da individualidade — os quais deveriam ser abandonados pelo advendo da MQ. Com efeito, em uma passagem de tal texto, extrai-se que "eu devo prevenir sobre um conceito errôneo (...) de que um amontoado [de partículas] impede-nos somente de registrar a identidade das partículas, e que confundimos uma partícula com a outra. O ponto é que elas não são indivíduos que possam ser confundidos uns com os outros. Uma tal afirmação (a de que seriam indivíduos de algum tipo) é sem sentido" (grifo meu).

Se aceitarmos tal não-individualidade e quisermos assim fundamentar uma teoria que destoante do caso clássico assuma esta posição desde o princípio, um modo de fazermos isso é nos voltarmos para a lógica subjacente à teoria. Como se sabe, nas teorias formais clássicas, um dos modos de se assumir a individualidade dos objetos é tomá-la a partir da auto-identidade dos mesmos, e deste modo uma das maneiras que existe para se considerar um objeto como um não-indivíduo é exatamente negarthe a auto-identidade: em especial, negar-lhe a lei reflexiva da identidade $\forall x(x=x)$ da lógica clássica. Com efeito, se assumirmos a fórmula " $a=a$ " em nosso sistema, então é possível provar que a expressão $\forall F(F(x) \leftrightarrow F(y)) \rightarrow x=y$ é teorema da lógica de segunda ordem e então não podemos ter objetos que partilhem de todas as propriedades sem serem o mesmo objeto. Assim, se quisermos ter o antecedente dessa fórmula - que informalmente expressa a noção de indiscernibilidade (concordância em todas as propriedades) - sem ter o conseqüente (a identidade), um modo possível é fazer uma imposição na sintaxe e assumir uma lógica não-reflexiva onde a fórmula " $a=a$ " não é considerada uma fórmula bem formada. Ao limitarmos o conceito de identidade deste modo, iremos poder elaborar uma teoria matemática na qual podemos falar de objetos indistinguíveis, mas não idênticos. É claro que es- 
tamos aqui adotando uma forte relação entre individualidade e identidade, de modo que estamos encampando a posição de que podemos caracterizar (sintaticamente) como não-indivíduos exatamente àquelas entidades (aqui representados por termos individuais da linguagem) para as quais a relação de auto-identidade " $a=a$ " não faz sentido. Todavia, é importante que se diga que com isto não queremos afirmar que um não-indivíduo é diferente de si mesmo, ${ }^{20}$ mas antes apenas que a 'propriedade' de ser idêntico a si mesmo não se aplica a esse tipo de entidade (da Costa et. al. 2012).

Também como dissemos, a semântica para esta lógica tem que ser construída em algum fundamento matemático alternativo; aqui em especial relacionado ao uso de uma teoria de conjuntos não-clássica onde a noção de não-indivíduo também passe a figurar adequadamente (ou seja, onde também não valha a lei reflexiva " $a=a$ " em nosso sistema). Como já enfatizado, uma tal teoria que se coaduna com os requisitos acima mostrados existe e se chama "teoria dos quase-conjuntos". Na próxima seção exploraremos a axiomática e alguns teoremas de tal arcabouço teórico de modo a entender como podemos nela expressar (sintaticamente) a não-individualidade dos objetos quânticos.

\section{A Teoria de Quase-Conjuntos}

Como falamos acima, a matemática clássica pode ser fundamentada em uma teoria de conjuntos, sendo em geral usada a teoria de de ZFC. ${ }^{21}$ Não obstante, como estamos mostrando, tal teoria conjuntista (e por conseguinte a matemática clássica) está fundamentada na lógica clássica, e de acordo com tais teorias se tivermos duas entidades deve haver uma diferença entre elas; o que se mostra problemático no contexto quântico. Motivados por razões distintas, da Costa (1980, p.117-20) discutiu a possibilidade de criar sistemas lógicos nos quais pudesse se restringir o princípio da identidade da lógica clássica de alguma forma. Suas motivações foram essencialmente filosóficas, a saber, tentando mostrar que as leis da lógica não são indeléveis e que podem ser violadas. Todavia, baseado também nas ideias de Schrödinger, da Costa propôs uma lógica na qual a identidade de proposições (tais como $a=b$ ) faria sentido somente para objetos do tipo (ou que representariam os) macroscópicos, enquanto que para outros (que têm sua interpretação intencional como denotando as partículas quânticas) a expressão $a=b$ simplesmente não é uma fórmula bem formada. Com relação à semântica, a qual é feita usualmente em uma teoria de conjuntos, da Costa propôs (mas não desenvolveu) uma teoria conjuntista alternativa também baseada em tal lógica reflexiva, teoria esta que ele chamou de Teoria de Quase-Conjuntos (ibid., p.119). A partir de 1990, esta teoria de conjuntos nãoclássica passou a ser desenvolvida por Décio Krause em vários trabalhos 1990, 1992, 1996, 2003, 2003a, ${ }^{22}$ tendo por finalidade (entre outras) explorar uma contraparte 
formal lógica e matemática para certas coleções de objetos nas quais a identidade e a diferença são noções sem sentido. Como Krause desenvolveu tal teoria tendo realmente como motivação a MQ, afeito com tal área da física um conceito mais fraco de indistinguibilidade foi então assumido, o qual valeria apenas para alguns tipos de elementos dos quase-conjuntos: exatamente os que interpretam as partículas elementares. Desta forma, a teoria de Krause foi pensada como um modo de tratar formalmente exatamente as coleções de partículas como as que pontuamos acima, a saber, em que seus elementos partilham de todas as suas propriedades, mas que ainda diferem em número, tornando-se assim objetos indistinguíveis mas não idênticos. Vejamos então alguns axiomas e resultados principais da teoria de quaseconjuntos na acepção de Krause, e posteriormente discutamos uma aplicação para a mesma. ${ }^{23}$

\subsection{Formalização da teoria $\mathfrak{Q}$}

A teoria de quase-conjuntos $\mathfrak{Q}$ (ou teoria dos qsets) é baseada na axiomática da teoria de ZFU. Os postulados lógicos são similares àqueles do cálculo de predicados de primeira ordem, porém sem identidade. Além disso, destoante da teoria ZFU padrão, a teoria de quase-conjuntos permite a existência de dois tipos de urelemente: os $m$-átomos (para os quais a identidade não se aplica, e como dito têm como representação intencional as partículas quânticas), e os $M$-átomos (que se comportam como os urelemente usuais de ZFU). Dois predicados unários primitivos expressam essa distinção: $m(x)$ e $M(x)$, respectivamente. Além disso, na linguagem também existem dois predicados binários: $\equiv$ (indistinguibilidade, tomado como primitivo) e $\in$ (pertinência), um símbolo funcional unário qc (quase-cardinalidade) e uma letra de predicado $Z$, tal que $Z(x)$ diz que $x$ é um conjunto normal de ZFU. Como a noção de identidade não se aplica para os $m$-átomos, e como sustentamos seções prévias que indivíduos são os objetos que 'respeitam' a noção de identidade da lógica clássica (em particular a lei reflexiva $\forall x(x=x)$ já que acreditamos que a identidade deve ser entendida em conformidade com algum tipo de lógica), os m-átomos são então entendidos como não-indivíduos na teoria dos qsets.

Na teoria $\mathfrak{Q}$, assume-se também um conceito de identidade extensional (representado por $=_{E}$ ) que é introduzido por definição. Tal conceito terá propriedades consoantes às da identidade padrão e ao conceito correspondente em ZFU para $M$-átomos, embora o mesmo conceito não possa fazer parte de enunciados quando tratamos de $m$-átomos. Isto é relevante porque dado que não se tem a identidade usual, mas apenas a extensional, a axiomática permitirá - como veremos - diferenciar entre os conceitos de identidade extensional e indistinguibilidade.

Na teoria em apreço um qset $x$ é definido como algo que não é um urelement. Tal qset pode ter um cardinal (o qual nomeamos como quase-cardinal: $q c(x)$ ), mas 
para o qual não se pode associar aos seus elementos um ordinal se ele for formado apenas por $m$-átomos indistinguíveis. O conceito de quase-cardinal é então também tomado como primitivo, pois não pode ser definido pelos meios usuais, isto é, por ordinais particulares tal como é feito na matemática clássica.

\subsubsection{Definições, axiomas e teoremas}

Vamos começar por descrever os detalhes formais da teoria $\mathfrak{Q}$ introduzindo algumas definições:

1. Definição de um qset: $Q(x)=_{d f} \neg(m(x) \vee M(x))$.

2. Qset puro (uma coleção de átomos indistinguíveis): $P(X)={ }_{d f} Q(x) \wedge \forall y(y \in$ $x \rightarrow m(y)) \wedge \forall y \forall z((y \in x \wedge z \in x) \rightarrow y \equiv z)$.

3. Dinge, ou 'conjuntos' ou Urelemente: $D(x)={ }_{d f} M(x) \vee Z(x)$ (estes são as 'coisas clássicas' na terminologia de Zermelo).

4. Um qset no qual os elementos também são qsets: $E(x)={ }_{d f} Q(x) \wedge \forall y(y \in$ $x \rightarrow Q(y))$.

5. Identidade extensional: $\left(x=_{E} y\right)=_{d f}(Q(x) \wedge Q(y) \wedge \forall z(z \in x \leftrightarrow z \in y)) \vee$ $\left(M(x) \wedge M(y) \wedge \forall_{Q} z(x \in z \leftrightarrow y \in z)\right)$, onde $\forall_{Q}$ é o quantificador universal relativizado à qsets.

6. Subqset: Para todos os qsets $x$ e $y, x \subseteq y={ }_{d f} \forall z(z \in x \rightarrow z \in y)$.

Os primeiros axiomas de $\mathfrak{Q}$; aqueles que 'governam' o comportamento dos nãoindivíduos indistinguíveis a partir da relação de indistinguibilidade dada acima são os seguintes:

(Q1) $\forall x(x \equiv x)$ [三 é reflexiva];

(Q2) $\forall x \forall y(x \equiv y \rightarrow y \equiv x)$ [三 é simétrica];

(Q3) $\forall x \forall y \forall z(x \equiv y \wedge y \equiv z \rightarrow x \equiv z)$ [三é transitiva], e

(Q4) $\forall x \forall y\left(x==_{E} y \rightarrow(A(x, x) \rightarrow A(x, y))\right)$, com as restrições sintáticas usuais, isto é, $A(x, x)$ é uma fórmula qualquer, e $A(x, y)$ advém de $A(x, x)$ pela substituição de algumas ocorrências livres de $x$ por $y$, dado que $y$ é livre para $x$ em $A(x, x)$.

A partir desse ponto alguns teoremas já podem ser provados (a maior parte será apenas enunciada aqui). Note-se entretanto que a reflexividade da identidade não é um teorema quando se trata de $m$-átomos, e portanto o sistema aqui apresentado é classificado como um sistema não-reflexivo. Além disso, para os objetos clássicos ( $M$ átomos e conjuntos), postulamos em $\mathfrak{Q}$ que a indistinguibilidade implica igualdade extensional (a conversa segue-se como teorema). Sendo assim, para quaisquer dois

Principia 17(1): 103-135 (2013). 
objetos clássicos da teoria $\mathfrak{Q}$, se eles forem indistinguíveis serão extensionalmente iguais, e todas as outras propriedades lógicas da igualdade clássica são provadas de modo usual para estes objetos.

Teorema 1. Se ou $Q(x)$ ou $M(x)$, então $x={ }_{E} x$.

(Q5) Nada é ao mesmo tempo um $m$-átomo e um $M$-átomo: $\forall x(\neg(m(x) \wedge M(x)))$.

Teorema 2. Se ou $Q(x)$ ou $M(x)$, então $\neg m(x)$.

(Q6) Os átomos são vazios: $\forall x \forall z(x \in y \rightarrow Q(y)){ }^{24}$

(Q7) Qsets nos quais os elementos são 'coisas clássicas' são qsets que podem ser entendidos como conjuntos clássicos e vice-versa: $\forall_{Q} x(\forall y(y \in x \rightarrow$ $D(y)) \longleftrightarrow Z(x))$.

A partir disso, de acordo com os tipos de elementos que ocorrem nos qsets, podemos classificá-los como: a) puros: os que contém apenas $m$-átomos indistinguíveis; b) standard: conjuntos usuais de ZFU (não contendo $m$-átomos), e c) qset usual: pode conter $m$-átomos, $M$-átomos e outros qsets como elementos. Sendo assim, a teoria de quase-conjuntos que apresentamos aqui 'contém' a teoria ZFU, e toda a matemática que pode ser desenvolvida em ZFU pode também ser desenvolvida nesta teoria alternativa que estamos considerando (na sua parte 'clássica'). ${ }^{25}$ Isso então significa que a teoria $\mathfrak{Q}$ se mostra como uma extensão da teoria de conjuntos clássica e não como uma 'antinomia' à mesma.

(Q8) Dinge indistinguíveis são extensionalmente idênticos: $\forall_{D} x \forall_{D} y(x \equiv y \rightarrow$ $\left.x={ }_{E} y\right)$.

Isso nos garante que para os Dinge a indistinguibilidade obedece a lei da substituição (Q4) acima, de modo que os objetos clássicos indistinguíveis — por também respeitarem a lei reflexiva da identidade - são substituíveis salva veritate.

Teorema 3. A relação de igualdade extensional (para Dinge) tem todas as propriedades da igualdade clássica.

A distinção entre identidade extensional e indistinguibilidade primitiva pode ser vista como segue, embora os detalhes formais completos possam ser visto nas obras citadas. Pelos axiomas e teoremas acima, a relação de indistinguibilidade $\equiv$ permite a substitutividade de todos os símbolos não-lógicos primitivos, exceto o de pertinência. Isto é, se $B$ é $m, M$ ou $Z$, então $B(x) \wedge x \equiv y \rightarrow B(y)$ é um teorema. Se isto fosse possível também para $\in$, então dado que $\equiv$ é reflexiva (axioma $(\mathrm{Q} 1)$ ), deveríamos ter substitutividade 'total' para $\equiv$ e esta não se tornaria diferente da identidade em

Principia 17(1): 103-135 (2013). 
sua forma usual (dito de outra forma, neste caso 'para todos os efeitos práticos' $\equiv$ colapsaria na identidade usual). Mas com relação à pertinência este não é o caso, já que de $x \in w \wedge y \equiv x$ não temos que $y \in w$, pois a teoria $\mathfrak{Q}$ não tem axiomas que permitam isso. Deste modo, e isso é importante, a indistinguibilidade para os $m$-átomos não se torna a identidade 'padrão', e quando precisarmos falar que temos "dois" objetos, por exemplo, isso nos conduzirá a sua discernibilidade e não a sua diferença (aqui na acepção antônima de igualdade) Arenhart \& Krause 2007. Não obstante, se estes objetos forem $M$-átomos, a relação primitiva de indistinguibilidade formalmente coincide com a identidade usual tal como visto French \& Krause 2006 p.280. Além disso, enquanto que os Dinge obedecem a lei da substituição, não podemos da mesma forma substituir os $m$-átomos indistinguíveis salva veritate (ou seja, eles não podem ser sempre intersubstituíveis). Com efeito, se esse fosse o caso, a reflexividade da relação de indistinguibilidade de (Q1), (Q2) e (Q3) acima resultaria que a indistinguibilidade e a identidade colapsariam na mesma relação. Para evitar isso, não postulamos uma lei de substituição para a indistinguibilidade, mas antes exigimos (por tais axiomas) que seja apenas uma relação de equivalência a qual não é uma congruência (ou seja, ela não é compatível com todas as relações da teoria).

(Q9) [Par fraco] Para todos $x$ e $y$, existe um qset nos quais os elementos são indistinguíveis ou de $x$ ou de $y: \forall x \forall y \exists_{Q} z \forall t(t \in z \leftrightarrow t \equiv x \vee t \equiv y)$

Denotamos este qset por $[x, y]$ para diferenciar da notação clássica. Quando $x$ e $y$ são Dinge, podemos usar a notação usual $\{\mathrm{x}, \mathrm{y}\}$. Vamos remarcar que $[x, y]$ denotam os qsets de elementos indistinguíveis ou de $x$ ou y e, em geral, podem conter mais que dois elementos.

(Q10) [O esquema da separação] Considerando as restrições sintáticas usuais sobre a fórmula $A(t)$, isto é, $A(t)$ sendo uma fórmula bem formada na qual $t$ é livre, o seguinte axioma é um esquema de axioma: $\forall_{Q} x \exists_{Q} y \forall t(t \in y \leftrightarrow$ $t \in x \wedge A(t))$.

Este qset é denotado como $[t \in x: A(t)]$. Quando é um conjunto usual, é denotado como $\{t \in x: A(t)\}$.

(Q11) [União] $\forall_{Q} x\left(E(x) \rightarrow \exists_{Q} y(\forall z(z \in y) \leftrightarrow \exists t(z \in t \wedge t \in x))\right)$.

Este qset é denotado por $\bigcup x$ ou por $u \cup v$ quando $t$ tem somente dois elementos (qsets) $u$ e $v$;

(Q12) [Conjunto potência] $\forall_{Q} x \exists_{Q} y \forall t(t \in y \leftrightarrow t \subseteq x)$.

Escrevemos $\mathscr{P}(x)$ para este qset.

Principia 17(1): 103-135 (2013). 


\section{Definição 1.}

i) Par ordenado: $\langle x, y\rangle=_{d f}[[x],[x, y]]$.

ii) Classe unitária fraca: $[x]=[x, x]$ (isto é, a coleção dos indistinguíveis de $x$ ).

iii) $x \times t=_{d f}[\langle z, u\rangle \in \mathscr{P} \mathscr{P}(x \cup y): z \in x \wedge u \in y]$.

Como no caso de $[x, y],[x]$ é o qset de todos os elementos indistinguíveis de $x$ e pode ter mais que um elemento. O mesmo pode ser dito do produto cartesiano de dois qsets etc. Os conceitos de interseção e diferença de qsets são definidos como do modo usual, tal que $(t \in x \cap y)$ se e somente se $t \in x \wedge t \in y$, e $(t \in x-y)$ se e somente se $t \in x \wedge t \notin y$.

As relações e funções não podem ser definidas na teoria de quase-conjuntos do mesmo modo como são feitas na matemática padrão. Isto porque se tivermos tratando com $m$-átomos, devido à falta de identidade para tais objetos nos conjuntos domínio e imagem, a função acaba por não poder distinguir entre argumentos e valores. Devido também à carência da identidade, relações de ordem não podem ser adequadamente definidos sobre um qset que tem m-átomos indistinguíveis como elementos (isso será de importância para nós no futuro, quando formos apresentar uma estrutura quase-conjuntista para mecânica quântica). Abaixo trabalharemos apenas com relações binárias, apesar de que as definições podem ser generalizadas para relações de qualquer aridade.

Definição 2. Um q-set $w$ é uma quase-relação (iremos chamar simplesmente de relação quando não houver possibilidade de confusão) entre $x$ e $y$ se satisfaz o seguinte predicado: $R(w)={ }_{d f} Q(w) \wedge \forall z\left(z \in w \rightarrow \exists u \exists v\left(u \in x \wedge v \in y \wedge z={ }_{E}\langle u, v\rangle\right)\right)$.

Como se sabe, relações são importantes para se caracterizar os atributos de elementos de certas coleções de objetos. Na teoria de conjuntos padrão, temos duas relações de ordem principais: a de ordem parcial e a de ordem total ou linear. Todavia, tais relações em particular não podem ser definidas sobre um qset nos quais os elementos são $m$-átomos indistinguíveis: como não podemos falar que $u$ e $v$ são distintos, não podemos afirmar que eles estão em alguma ordem linear, por exemplo. Além disso, quando consideramos conjuntos clássicos, podemos (no mínimo em princípio) sempre 'rotular' qualquer elemento por associar sua classe unitária a ele (por exemplo, associar $\{x\} \operatorname{com} x$ ). Em teorias extensionais onde vale a identidade, esta classe unitária pode ser vista como uma 'propriedade' de $x$ somente. Desta forma, em ZF, todos os objetos podem ser distinguidos um dos outros (entre outros motivos) porque sempre existe um conjunto no qual apenas um objeto pertence: a saber, a sua correspondente classe unitária. ${ }^{26}$ Todavia, em $\mathfrak{Q}$, se $x$ for um $m$-átomo isso não pode ser afirmado: não podemos garantir (a partir da axiomática) que uma "classe unitária forte de $[x] " 27$ tenha apenas o indivíduo (ressalta-se: indivíduo) $x$ 
em particular. Outrossim, quando dizemos que $\langle u, v\rangle \in w$, devemos lembrar que pela definição de par ordenado dada acima isso significa $[[u],[u, v]]$. Todavia, desde que $u \equiv v$, este par é indistinguível (a partir do "Axioma da Extensionalidade Fraca" a ser apresentado abaixo) de $[[v],[v, u]]$, o qual é o 'par ordenado' $\langle v, u\rangle$. Além disso, este qset é também indistinguível de $[[u]]$, isto é, do par $\langle u, u\rangle$. A teoria não implica que $\langle v, u\rangle$ (ou $\langle u, u\rangle$ ) também pertençam a $w$, mas o que importa é que a relação $w$ é indistinguível das relações $w^{\prime}$ e $w^{\prime \prime}$ as quais têm esses 'outros' pares como elementos. Isso significa que qualquer ordem estrita total $w$ sobre um qset $x$ de $m$-átomos indistinguíveis, tal que $\langle u, v\rangle \in w$, é confundida na teoria com qualquer outra $w^{\prime}$, tal que $\langle v, u\rangle \in w^{\prime}$ (o mesmo acontece para $w^{\prime \prime}$ ). Assim, como afirmado, nenhuma ordem podem ser dita fazer sentido para os elementos de $\mathfrak{Q}$, pois a teoria não pode distinguir entre uma ordem definida em uma direção de qualquer outra que tem seus elementos em ordem 'reversa' French \& Krause 2006 p.281ss.

Definição 3 (quase-funções). Se $x$ e $y$ são qsets, e $R$ é um predicado para 'relação' definida acima, dizemos que $f$ é uma quase-função ( $q$-função) com domínio $x$ e contra-domínio y se satisfaz o seguinte predicado: $Q F(f)={ }_{d f} R(f) \wedge \forall u(u \in x \rightarrow$ $\exists v(v \in y \wedge\langle u, v\rangle \in f)) \wedge \forall u \forall u^{\prime} \forall v \forall v^{\prime}\left(\langle u, v\rangle \in f \wedge\left\langle u^{\prime}, v^{\prime}\right\rangle \in f \wedge u \equiv u^{\prime} \rightarrow v \equiv v^{\prime}\right)$.

Podemos, a partir disso, definir q-funções 'tipo' $q$-injetoras e $q$-sobrejetoras, de modo a assim também definir $q$-funções $q$-bijetivas tal qual na matemática clássica.

\subsubsection{Extensionalidade fraca}

Se $x$ é um qset no qual os elementos são indistinguíveis um do outro (vamos supor novamente que $q c(x)={ }_{E} n$ ), então as classes unitárias $y \subseteq x$ são indistinguíveis uma das outras como se segue do axioma da extensionalidade fraca (Q13) abaixo. Então todas as classes unitárias, do ponto de vista intuitivo, pareceriam 'cair' somente em um qset. Não obstante, tal incongruência se mostra enganosa, já que devemos lembrar que estes 'singletons' (subqsets que têm quase-cardinalidade 1) não são idênticos (isto é, eles não podem ser provados como sendo o mesmo objeto na teoria), mas sim apenas que são indistinguíveis em um sentido preciso.

A inexistência de um conceito de identidade para os $m$-átomos requer uma modificação axioma usual da Extensionalidade da teoria de conjuntos padrão que aqui não vale. ${ }^{28}$ Para tanto, faz-se então necessário introduzirmos a seguinte definição:

Definição 4. Para todos os qsets $x$ e $y$ não vazios:

i) $\operatorname{Sim}(x, y)=_{d f} \forall z \forall t(z \in x \wedge t \in y \rightarrow z \equiv t)$ (neste caso dizemos que $x$ e $y$ são similares.)

ii) $\operatorname{QSim}(x, y)=_{d f} \operatorname{Sim}(x, y) \wedge q c(x)=_{E} q c(y)$ (isto é, $x$ e $y$ são $q$-similar se, e somente se, são similares e têm a mesma cardinalidade).

Principia 17(1): 103-135 (2013). 
No axioma abaixo, $x / \equiv$ significa o qset quociente de algum qset $x$ pela relação de equivalência $\equiv$.

(Q13) [Extensionalidade Fraca] Qsets que têm a mesma quantidade de elementos do mesmo tipo são indistinguíveis: $\forall_{Q} x \forall_{Q} y\left(\left(\forall_{z}(z \in x / \equiv \rightarrow \exists t(t \in y / \equiv\right.\right.$ $\wedge Q \operatorname{Sim}(z, t)))) \wedge \forall t(t \in y / \equiv \rightarrow \exists z(z \in x / \equiv \wedge Q \operatorname{Sim}(t, z))) \rightarrow x \equiv y)$.

Como dito, este axioma exprime a ideia intuitiva de que dois qsets $A$ e $B$ serão indistinguíveis se, e somente se, possuírem a mesma quantidade (expressa por meio de quase-cardinais) de elementos do mesmo tipo. É fácil ver que se não temos $m$ átomos evolvidos, então a relação $\equiv$ se torna a identidade usual e o axioma coincide com o axioma padrão da extensionalidade usado em ZF. Não obstante, se tais qsets forem compostos por $m$-átomos, devido aos motivos já expostos não conseguimos deste axioma provar que tais qsets são o mesmo qset tal como pode ser feito na teoria de conjuntos clássica. Uma das principais aplicações do axioma da extensionalidade fraca é o teorema da "não observabilidade das permutações" que será aqui apenas enunciado (a prova pode ser vista na bibliografia citada). Tal teorema acaba por prover um modo de representar, a partir da teoria de quase-conjuntos, a ideia de que se um certo objeto de um qset é 'permutado' por um outro indistinguível dele então 'nada muda no qset final'. Do ponto de vista formal, nas teorias de conjunto padrão, podemos expressar tal ideia dizendo que se $w \in x$, então $[(x-\{w\}) \cup\{z\}=x]$ se e somente se $z=w$. Deste modo, nas teorias formais clássicas, só se pode trocar (sem modificar o arranjo final) dois elementos se eles são o mesmo elemento (por força do axioma da extensionalidade clássico já citado). Mas no caso dos quase-conjuntos, como enfatizamos, a partir do teorema da não observabilidade das permutações, um objeto pode ser permutado por outro indistinguível (mas não necessariamente o mesmo) sem necessitarmos assumir hipóteses ad hoc externas à axiomática: ${ }^{29}$

Teorema 4 ((não-observabilidade de permutações)). Seja $x$ um qset finito tal que $x \neq_{E}[z]$, e z um m-átomo tal que $z \in x$. Se $w \equiv z$ e $w \notin x$, então existe $u m w^{\prime}$ tal que $\left(x-z^{\prime}\right) \cup w^{\prime} \equiv x$.

Intuitivamente, este teorema diz que se $x$ tem $n$ elementos, então se 'trocarmos' os elementos $z$ pelos correspondentes elementos indistinguíveis $w$ (do ponto de vista conjuntista, isto significa fazer a operação $\left.\left(x-z^{\prime}\right) \cup w^{\prime}\right)$, então o qset resultante permanece indistinguível do original. Em certo sentido, de um ponto de vista pragmático, não é importante se é com $x$ ou com $\left(x-z \cup w^{\prime}\right)$ que estamos lidando, o que basicamente reflete a atitude do físico. Deste modo, a grande diferença está exatamente no fato de que na teoria de quase-conjuntos "para que não se mude o conjunto final", basta que os objetos permutados sejam indistinguíveis entre si, como dito.

Principia 17(1): 103-135 (2013). 
Esta seção foi apenas expositiva, onde apresentamos algumas facetas do formalismo de uma teoria de conjuntos alternativa que, como enfatizamos, parece se coadunar de um modo mais natural com a 'realidade quântica' ao assumir objetos 'desprovidos da identidade' desde o início. ${ }^{30}$ Não obstante, para a discussão tida neste trabalho, é interessante ver o alcance de tal teoria no que se refere a algumas outras possibilidades de aplicação da mesma. Em particular, na próxima seção, construiremos uma estrutura quase-conjuntista que parece refletir as características teóricas da MQ, e posteriormente discutiremos algumas vantagens de tal construção perante o formalismo clássico.

\section{Uma estrutura matemática quase-conjuntista para a MQ não relativista}

Em questões de fundamentos, tem sido comum o emprego de estruturas matemáticas para de obtermos o 'esqueleto formal' de certas áreas do conhecimento. Com efeito, o uso de tal arcabouço, tornou-se hoje em dia uma das formulações mais em voga para se entender o que são e como funcionam as teorias científicas, a ponto de alguns filósofos defenderem que boa parte da ciência aplicada poderia ser reduzida ao conceito matemático de estrutura. ${ }^{31}$ Claro que uma questão pertinente é exatamente como ligar os 'objetos' de tal estrutura com a realidade empírica, haja vista que uma estrutura matemática é um objeto abstrato vivendo numa hierarquia conjuntista, enquanto que a realidade empírica não é. Trata-se de uma pergunta de difícil resposta e para a qual não há consenso: os antigos positivistas lógicos, por exemplo, falavam em relações coordenadoras para atribuir um certo conteúdo empírico a pelo menos alguns termos teóricos (Suppe 1977), mas a questão é delicada e não há pleno consenso sobre como vincular as nossas teorias com 'realidade'. Isso, no entanto, não impede a prática científica, bem como não invalida uma tentativa de se estruturar de um modo matemático/conjuntista certas teorias científicas. Sendo assim, deixando essa discussão de lado, para os propósitos tidos neste trabalho nos basta saber que uma estrutura matemática é um objeto de natureza conjuntista, sendo do ponto de vista formal usualmente definida como uma $n$-upla ordenada composta de um domínio e de relações sobre os objetos de tal domínio (que podem ser caracterizados como particulares sub-conjuntos do domínio da estrutura, as quais (grosso modo) podem ser entendidas como refletindo as relações existentes entre os objetos de uma certa parcela da realidade em estudo), exprimindo com isso a essência da teoria científica em apreço. ${ }^{32}$ Desta feita, uma estrutura matemática é algo fundamentado numa teoria de conjuntos, e os preceitos da teoria de conjuntos que estamos em particular utilizando acabam por também ficar 'atrelados' à nossa estrutura: daí a importância — dada a discussão acima — de fundamentarmos uma 
estrutura para a MQ em uma teoria de quase-conjuntos onde não nos comprometeríamos com as noções de identidade e individualidade para seus objetos básicos.

Em geral, de acordo com os objetos e relações que assumimos como válidos sobre o domínio, podem existir diversos modos possíveis de se erigir uma estrutura para uma teoria científica, ${ }^{33}$ o mesmo então acontecendo para uma possível 'estrutura quântica'. Aqui, nos contentaremos em dar dois exemplos (um terceiro pode ser visto em Dalla Chiara \& di Francia 1979), e posteriormente discutiremos rapidamente a diferença e as características de cada um deles.

Sendo assim, no sentido aqui exposto, do ponto de vista matemático um dos modos de se entender estruturalmente a mecânica quântica não-relativista pode ser a seguinte (Krause \& Arenhart 2012):

$$
Q M_{N R}=\left\langle S,\left\{\mathscr{H}_{i}\right\},\left\{A_{i j}\right\},\left\{T_{i k}\right\}\right\rangle_{i \in I, j \in J, k \in K},
$$

onde $S$ é um conjunto de sistemas físicos; $\left\{\mathscr{H}_{i}\right\}$ é uma coleção de espaços de Hilbert; $\left\{A_{i j}\right\}$ é uma coleção de operadores Hermitianos sobre o espaço $\mathscr{H}_{i}$, e $\left\{T_{i k}\right\}$ é uma coleção de operadores unitários sobre $\mathscr{H}_{i}$, tal que $\left\{T_{i k}\right\} \subset\left\{A_{i j}\right\}$, de modo que os seguintes 'axiomas' sejam satisfeitos (MacMahon 2006 p.205ss, Krause \& Arenhart 2012, Mackey 1963 p.63ss e Toraldo di Francia 1981 p.270ss):

1. Para cada sistema físico $s \in S$, associamos um espaço de Hilbert complexo $\mathscr{H}_{s} \in\left\{\mathscr{H}_{i}\right\}$. Os vetores $|\psi\rangle,|\chi\rangle$ etc. deste espaço representam os estados do sistemas físico e são chamados (os vetores) de vetor de estado do sistema: eles representam tudo o que sabemos sobre o sistema. Tais vetores são normalizados, de modo que para qualquer número complexo $k, k \cdot|\psi\rangle$ representa o mesmo estado que $|\psi\rangle$. Quando temos um sistema composto por diversos elementos de $S$, associamos a ele o produto tensorial dos espaços de Hilbert de cada um dos elementos do sistema (tal como vimos quando discutimos acima a não comutatividade do produto tensorial).

2. Tenha $|\psi(t)\rangle$ representando o estado do sistema no tempo $t .{ }^{34}$ Então para cada $|\psi\rangle$, associamos um operador unitário $T_{s}$, tal que para qualquer instante de tempo $t$, temos que

$$
|\psi(t)\rangle=T_{s}(t) \cdot|\psi(0)\rangle,
$$

onde $|\psi(0)\rangle$ é o estado do sistema no tempo $t=0$ (estado inicial). Esta expressão representa a evolução unitária no tempo do vetor de estado e é determinística. Na verdade, tal equação é uma forma abreviada da chamada equação de Schrödinger, que em uma das formas pode ser escrita como

$$
i \hbar \frac{\partial}{\partial t}|\psi\rangle=H|\psi\rangle,
$$

Principia 17(1): 103-135 (2013). 
onde $\hbar=h / 2 \pi$ (sendo $h$ a constante de Planck); $i$ é o número complexo igual a $\sqrt{-1} ; \partial / \partial t$ é a diferenciação parcial em relação ao tempo agindo sobre $|\psi\rangle$ e representa exatamente a razão de mudança de $|\psi\rangle$ com respeito ao tempo, e $H$ é o operador Halmiltoniano que expressa a energia total do sistema (cf. Penrose 1989 p.372).

3. Os autovalores de $A$, isto é, aqueles escalares reais $a_{i}$ tal que $A\left|\psi_{i}\right\rangle=a_{i} \cdot\left|\psi_{i}\right\rangle$, são os possíveis resultado da medição de $A$. Assume-se que um operador Hermitiano representa quantidades físicas observáveis que podem ser medidas sobre o sistema em um certo estado.

4. É sabido que qualquer hermitiano $A$ é diagonalizável, o que significa que podemos encontrar uma base $\left\{\left|\alpha_{i}\right\rangle\right\}$ para o espaço de Hilbert considerado formado pelos autovetores de $A$. Desta forma, para qualquer estado $|\psi\rangle$, escrevemos $|\psi\rangle=\sum_{i} c_{i}\left|\alpha_{i}\right\rangle$, onde $c_{i}=\left\langle\alpha_{i} \mid \psi\right\rangle$ são os coeficientes de Fourier. Além disso, temos $\left|c_{i}\right|^{2}=P_{i}$ representando a probabilidade de que uma medição de $A$ dê o valor $a_{i}$. Este último postulado é conhecido como regra de Born.

5. Se a medição de uma quantidade física $A$ dá o resultado $a_{i}$, o vetor de estado $|\psi\rangle$ torna-se $\left|a_{i}\right\rangle$ imediatamente após a medição. Isto é conhecido como o colapso do vetor de estado.

Como dito acima, podem existir variações para esta estrutura de acordo com o forma que descrevemos os postulados/axiomas, ou o que assumimos como pertencente à $n$-upla da estrutura. Com efeito, prof. Newton da Costa, ${ }^{35}$ por exemplo, apresenta uma estrutura quântica (ou um "sistema quântico abstrato") da seguinte forma:

$$
\mathfrak{M}=\left\langle\mathscr{P}, \mathbb{R}^{3}, T, \mathscr{H}, \psi, H\right\rangle,
$$

onde

(i) $\mathscr{P}$ é um conjunto de $n$ objetos chamados de partículas;

(ii) $\mathbb{R}^{3}$ é o espaço euclidiano a três dimensões;

(iii) $T$ são intevalos do conjunto dos reais cujo os elementos constituem os instantes de tempo (o que abstratamente vai então corresponder à noção de tempo),

(iv) $\mathscr{H}$ é um espaço de Hilbert em geral separável e complexo,

(v) $\psi$ é um vetor no espaço de Hilbert $\mathscr{H}$ (isto é, $\psi \in \mathscr{H}$ ) chamado de vetor de estado (ou função de onda) do sistema quântico em apreço, e

(vi) $H$ é o hamiltoniano do sistema físico (também a ser caracterizado de acordo com o sistema em estudo), 
tudo isso satisfazendo os axiomas do exemplo anterior que podem ser facilmente adaptados para esta estrutura. Segundo prof. da Costa, estudar a MQ significa estudar estruturas desse tipo (entre outras coisas, estudar por exemplo os resultados advindos das relações que existem entre os 'objetos' desta estrutura, bem como as extensões da mesma, ou qual parcela da realidade tal estrutura reflete etc. ${ }^{36}$ ).

Um dos primeiros pontos a ser ressaltado é o fato de que nesta última formulação temos clara menção à noção de "partícula" (ou a um conjunto delas), enquanto que no primeiro exemplo aparece apenas a noção de "sistema físico". Esta diferença não é desproposital, haja vista que a questão sobre qual é o "objeto quântico" (ou sobre o que a MQ trata) é complexa e bem pouco consensual. Só para citar alguns exemplos, na mecânica quântica que estamos trabalhando, isto é, a dita ortodoxa ou não relativista, os objetos quânticos são entendidos como sendo realmente partículas (ou algo próximo a isso); mas na chamada Mecânica Quântica de Campos (ou Mecânica Quântica Relativística), o que temos por sua vez são ondas (sem partícula); em sentido semelhante, Schrödinger, durante muito tempo, acreditou que a sua equação de onda descrevia uma onda real, mas depois abandonou esta suposição (veja Wick 1996 cap.4); para outros físicos, o que temos são apenas medidas de probabilidade, ou excitações em um campo (sem 'objeto' propriamente), e assim por diante, a ponto de Newton da Costa afirmar, inclusive, que "cada axiomática é um tipo de comprometimento da pessoa com uma visão da MQ em particular". ${ }^{37}$ Desta feita, como estamos trabalhando na MQ ortodoxa, vamos então assumir — de um ponto de vista heurístico - a posição de que a MQ trabalha com um objeto que pode ser entendido como um 'tipo' de partícula, suposição esta que como vimos é realmente adotada por alguns físicos.

Se aceitarmos tal ideia, e acatarmos assim a visão de que os objetos quânticos podem ser entendidos como partículas de algum modo, como a teoria dos quaseconjuntos - em especial aqui relacionada ao uso das estruturas matemáticas pode ser aplicada no estudo de tais aspectos? Vamos considerar a 'segunda' estrutura acima, a qual representa a mecânica quântica não relativista corpuscular, por assim dizer. A partir da discussão dada nas seções prévias, vimos que podemos defender a ideia de que os membros do conjunto (domínio) $\mathscr{P}$ da estrutura (ou seja, as partículas) carecem da noção de identidade, e que é assim problemático fundamentar tal arcabouço (já que, repetimos, uma estrutura matemática é um conceito conjuntista) em um teoria de conjuntos clássica como ZFC. Sendo assim, podemos sensatamente defender a posição de que a estrutura acima deva ser fundamentada na teoria de quase-conjuntos, de modo que o conjunto $\mathscr{P}$ seja então um qset que pode representar partículas indistinguíveis ( $m$-átomos) do mesmo tipo ou de tipo diverso (que poderiam assim ser interpretados como os nossos prótons, elétrons e nêutrons). Este qset tem um cardinal: para as aplicações em física, finito, de modo que a quase-cardinalidade dele é igual a $n$. Sendo assim, como a estrutura acima 
especificada (bem como as outras que poderiam ser erigidas) podem ser fundamentadas em $\mathfrak{Q}$, mesmo sem sermos hábeis em discernir os elementos de $\mathscr{P}$, podemos associar a cada um deles um espaço de Hilbert $\mathscr{H}_{i}$ e o resto do esquema pode ser construído da mesma forma. A diferença aqui é que enquanto que numa estrutura clássica os objetos são indivíduos na acepção plena da palavra, na estrutura quaseconjuntista não temos este comprometimento com a individualidade dos mesmos, e isso traz um ganho conceitual a partir de uma assunção mais 'natural' das características dos sistemas microscópicos que pontuamos neste artigo.

Uma outra vantagem da abordagem estrutural quase-conjuntista que pode ser mencionada aqui é a que se refere à questão da rigidez das estruturas matemáticas, a qual — em linhas gerais — funciona do seguinte modo. ${ }^{38}$ Dada uma estrutura $\mathfrak{U}=\left\langle D, R_{i}\right\rangle_{i \in I}$, um automorfismo em $\mathfrak{U}$ é uma função bijetiva $h: D \rightarrow D$, tal que se $R_{i}\left(x_{1}, \ldots, x_{n}\right)$, então $R_{i}\left(h\left(x_{1}\right), \ldots, h\left(x_{n}\right)\right)$ para toda relação $R_{i}$ de aridade $n$. Dito de forma coloquial, um automorfismo na estrutura $\mathfrak{U}$ é uma bijeção de $D$ em $D$ que preserva cada função, cada relação e o complementar de cada relação de $\mathfrak{U}$, de modo que desta forma se preserve (entre outras coisas) a ordem da relação, e de modo que assim as 'duas' estruturas fiquem 'estruturadas da mesma forma'. Se o único automorfismo que existir na estrutura for a função identidade, na qual é possível ver de pronto que tais condições são trivialmente satisfeitas, a estrutura é dita ser rígida. Por exemplo, no caso de uma espécie de estrutura de grupos, suponha que definimos uma estrutura tendo como domínio o conjunto $\mathbb{Z}$ dos inteiros, e como relação a operação + de adição de inteiros, obtendo assim $\mathfrak{Z}=\langle\mathbb{Z},+\rangle$. Uma função $f: \mathbb{Z} \mapsto \mathbb{Z}$ definida por $f(x)=-x$ para $\forall x \in \mathbb{Z}$ é um automorfismo em $\mathfrak{Z}$. Então podemos mostrar que esta estrutura tem dois automorfismos: a função identidade $i(x)=x$ (que é sempre um automorfismo), e a função $f(x)=-x$. Tais dois automorfismos presentes fazem com que essa estrutura não seja rígida: nesta estrutura, para qualquer que seja $x \in \mathbb{Z}$, temos que $x$ e $-x$ são $\mathfrak{Z}$-indistinguíveis na (ou pela) estrutura em questão. ${ }^{39}$ Todavia, sabemos que 2 e -2 , por exemplo, são diferentes, mas isto não pode ser visto a partir desta estrutura particular. Não obstante, um teorema muito importante de da Costa \& Rodrigues 2007 prova que toda estrutura não-rígida em ZFC pode ser estendida a uma estrutura rígida pelo finito acréscimo de relações de primeira ordem, de modo que assim o único automorfismo presente na estrutura se torne a função identidade. ${ }^{40}$

Entre outras coisas, tal resultado mostra que se quiséssemos utilizar do artifício do exemplo acima para fundamentar objetos indistinguíveis (ou seja, adotando estruturas clássicas que tenham automorfismos distintos da função identidade), tais estruturas sempre podem ser expandidas à estruturas rígidas nas quais se pode 'identificar' e individualizar (em tal rigidificação) os objetos do domínio de modo absoluto (nem que seja 'de fora' da estrutura original, isto é, no 'universo' de ZFC que é onde tal estrutura está fundamentada). Basicamente, isto quer dizer que em ZFC não po- 
demos ter não-indivíduos legítimos.

Todavia, é fácil ver que se tivermos uma estrutura na qual seu domínio seja composto por $m$-átomos, esta não pode ser rígida. Com efeito, como em uma $q$-função não temos a noção de identidade para os elementos, isto não permite que o único objeto invariante de $x$ em um automorfismo seja o próprio $x$, por exemplo, fato que faz com que a definição acima de estrutura rígida não seja aqui satisfeita. Além disso, é possível provar que o teorema de da Costa \& Rodrigues antes citado aqui não tem efeito (entre outros motivos, devido principalmente ao fato de não podermos ter relações de ordem em um q-set, tal como enfatizamos na seção anterior), fato que não permite uma rigidificação de uma estrutura quase-conjuntista - e assim uma 'identificação' de seus elementos — de nenhuma forma. Isto é importante, pois caso esse teorema clássico também se consagrasse para o caso quase-conjuntista, uma forma 'sorrateira' de identidade — por assim dizer — poderia ser impingida sobre os $m$-átomos das estruturas através de tal manobra, fato que levaria a intenção formal da teoria $\mathfrak{Q}$ à derrocada. ${ }^{41}$ Em suma, essa não-rigidez mostra que podemos realmente afugentar o 'fantasma da identidade' para as teorias fundamentadas em $\mathfrak{Q}$. A inexistência de uma possibilidade de rigidificação das estruturas quase-conjuntistas, somada ao fato da assunção de uma não-individualidade $a b$ initio, mostra que esta teoria é um fundamento seguro para uma formalização mais condizente com a realidade da MQ.

\section{Conclusão}

Durante esta discussão, o que se objetivou foi tentar tratar de um modo formal a falta de identidade para as partículas quânticas e estudar o 'alcance' de tal intento em uma de suas frentes conjuntistas, a saber, relacionada a uma estruturação matemática para a mecânica quântica. No caso aqui estudado, defendemos a posição de que devemos buscar tal fundamentação por uma teoria de quase-conjuntos (a qual tem por base uma lógica não-reflexiva), teoria esta em que podemos assumir partículas que são 'naturalmente' desprovidas de identidade. Tal questionamento é importante, haja vista que toda a discussão que apresentamos é relacionada exatamente à problemática existente em fundamentarmos a MQ em teorias clássicas onde a noção de identidade e individualidade é perene, e onde por isso se faz necessário usar artifícios que apenas encobrem o problema. Vários argumentos foram dados mostrando que tal abordagem clássica é problemática para essas disciplinas, e acreditamos que outras questões sobre qual o melhor fundamento conjuntista e lógico, como tais alicerces se intercalariam, bem como quais são os alcances das construções feitas em um ou em outro fundamento se mostram bastante frutíferas para o filósofo da ciência desprezá-las.

Principia 17(1): 103-135 (2013). 


\section{Referências}

Arenhart, J. B.; Krause, D. 2007. Identidade, individualidade e quase-conjuntos. Revista Eletrônica Informação e Cognição 6(2): 25-39.

Bell, J. S. 1987. Speakable and unspeakable in quantum mechanics. Cambrigde: Cambrigde University Press.

Bitbol, M. 1996. Mécanique quantique: une introduction philosophique. Paris: Flammarion.

—. 2001. Jean-Louis Destouches: théories de la prévision et individualité. Philosophia Scientiae 5: 1-30.

Black, M. 1952. The identity of indiscernibles. Mind 61: 153-64.

Cross, R. 2010. Medieval Theories of Haecceity. In: N. E. Zalta (ed) The Stanford enciclopedia of philosophy. Disponível em: http://plato.stanford.edu/archives/fal2010/entries/medieval-haecceity/. Acessado em 29/12/2012.

da Costa, N. C. A. 1980. Ensaio Sobre os Fundamentos da Lógica. São Paulo: Hucitec/EdUSP.

da Costa, N. C. A.; French, S. 2003. Science and Partial Truth: a Unitary Approach to Models and Scientific Reasoning. Oxford: Oxford University Press.

da Costa, N. C. A.; Krause, D.; Arenhart, J. B.; Schinaider, J. 2012. Sobre uma fundamentação não reflexiva da mecânica quântica. Scientiae Studia 10(1): 71-104.

da Costa, N. C. A.; Rodrigues, A. A. M. 2007. Definibility and invariance. Studia Logica 86: $1-30$.

Dalla Chiara, M. L.; Toraldo di Francia, G. 1979. Formal analysis of physical theories. In: G. Toraldo di Francia (ed.) Problems in the Foundations of Physics. Amsterdam: NorthHolland.

—. 1993. Individuals, kinds and names in physics. In: G. Corsi; M. L. Dalla Chiara; G. C. Ghirardi (eds.) Bridging the Gap: Philosophy, Mathematics, and Physics (Boston Studies in the Philosophy and History of Science) 140, Part III, p.261-83.

Destouches, J.-L. 1948. Quelques aspects théoriques de la notion de complémentarité. Dialectica 2(3-4): 351-82.

-1960. La Mécanique Ondulatoire. Paris: PUF.

French, S.; Krause, D. 2006. Identity in Physics: a Historical, Philosophical and Formal Analysis. New York: Oxford University Press.

Heelan, P. A. 1970. Complementarity, context dependence and quantum logic. Foundations of Physics 1(2): 95-110.

Jammer, M. 2010. Conceito de Espaço: a História das Teorias do Espaço na Física. São Paulo: Livraria da Física Editora (1953).

Krause, D. 1990. Não-reflexividade, Indistinguibilidade e Agregados de Weyl (tese de Doutorado). São Paulo: USP.

- 1992. On a quasi-set theory. Notre Dame Journal of Formal Logic 33: 402-11.

. 1996. Axioms for collections of indistinguishable objects. Logique et Analyse 153-54: 69-93.

- 2003. Why quasi-sets? Boletim da Sociedade Paranaense de Matemática 20: 73-92.

- 2003a. The mathematics of non-individuality. In: Coleção Documentos: Série Lógica e Teoria da Ciência 46, São Paulo: Instituto de Estudos Avançados da Universidade de São Paulo.

Principia 17(1): 103-135 (2013). 
Krause, D.; Arenhart, J. B. 2012. A discussion on quantum non-individuality. Journal of Applied Non-Classical Logics 22(1-2): 105-24.

Mackey, G. W. 1963. The Mathematical Foundations of Quantum Mechanics. New York: W. A. Benjamin, Inc.

MacMahon, D. 2006. Quantum Mechanics Desmistified. New York: McGraw-Hill.

Magalhães, J. C.; Krause, D. 2001. Suppes predicate for genetics and natural selection. Journal of Theoretical Biology 209(2): 141-53.

Malin, S. 2001. The Nature Loves to Hide: Quantum Physics and Reality, a Western Perspective. New York: Oxford University Press.

Penrose, R. 1989. The Emperor's New Mind. London: Vintage.

Pessoa Jr., O. 2003. Conceitos de Física Quântica. São Paulo: Livraria da Física Editora.

—. 2006. Conceitos de Física Quântica (vol. 2). São Paulo: Livraria da Física Editora.

Post, H. 1963. Individuality and physics. The Listener: 534-7. Reimpresso em Vedanta for East and West 132: 14-22, 1973.

Quinton, A. 1973. The Nature of Things. London: Routledge and Kegan Paul.

Redhead, M.; Teller, P. 1991. Particles, particle labels, and quanta: the toll of unacknowledged metaphysics. Foundations of Physics 21: 43-62.

- 1992. Particle labels and the theory of indistinguishable particles in quantum mechanics. British Journal for the Philosophy of Science 43: 201-18.

Reichenbach, H. 1944. Philosophic Foundations Of Quantum Mechanics. Berkeley: University of California Press.

Russell, B. 1978. Análise da matéria. Rio de Janeiro: Zahar Editores.

Schiller, C. 2009. Motion Mountain: the Adventure of Physics. Disponível em http://www.motionmountain.eu.

Schrödinger, E. 1957. What is an elementary particle? In: Science and the Human Temperament. New York: Dover Publications.

Suppes, P. 1957. Introduction to Logic. New York: van Nostrand Reinhold Company.

Suppe, F. (editor). 1977. The Structure of Scientific Theories. Illinois: Un. Illinois Press, $2^{a}$ ed.

Teller, P. 1995. An Interpretative Introduction to Quantum Field Theory. Princeton: Princeton University Press.

Toraldo di Francia, G. 1981. The Investigation of the Physical World. Cambridge: Cambridge University Press.

Uffink, J. E.; Hilgevoord, J. 1988. Interference and indistinguishability in quantum mechanics. Physica B: 309-13.

Wick, D. 1996. The Infamous Boundary. New York: Copernicus.

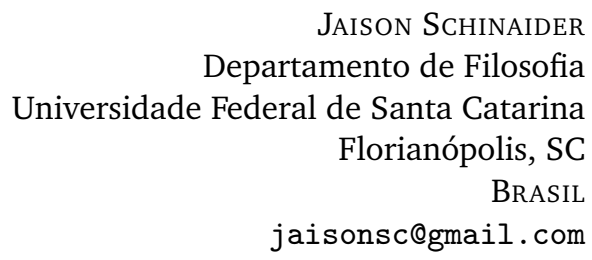

Resumo. Neste artigo são discutidas algumas questões acerca da natureza das partículas elementares tratadas pela mecânica quântica, em especial relacionadas aos conceitos de

Principia 17(1): 103-135 (2013). 
identidade e individualidade das mesmas. Iniciamos expondo brevemente as concepções filosóficas e formais acerca da identidade e individualidade, e, posteriormente, mostramos como essas noções são problemáticas quando aplicadas às partículas elementares como elétrons, prótons e nêutrons. Em particular, enfatizamos que tanto a filosofia, bem como a lógica e a teoria de conjuntos (e, assim, a matemática nessas últimas fundamentadas), partem do pressuposto usual que as coisas têm um 'tipo' de identidade e de individualidade (isto é, são indivíduos), no sentido de que objetos que tenham todas as mesmas propriedades são o mesmo objeto (são iguais). Não obstante, mostramos que no universo quântico é possível encontrar objetos que partilham de todas as suas propriedades, mas que não são apenas um, se constituindo tais objetos quânticos em algo como "não-indivíduos" (tese atualmente defendida por vários físicos e filósofos da ciência). Em seguida, mostramos como a matemática clássica - a qual, como dito, pressupõe uma individualidade para seus entes - se comporta perante esta situação; em particular admitindo pressupostos externos às teorias. Para se evitar tal procedimento, e assim buscar um formalismo mais 'natural' e adequado para se trabalhar com essas características, sugerimos o uso de uma teoria de conjuntos não-clássica chamada de teoria de quase-conjuntos, que baseada em uma lógica não-reflexiva, admite objetos desprovidos de identidade e individualidade $a b$ initio. Por fim, mostramos uma outra aplicação para essa teoria, agora relacionada à busca por uma estrutura matemática quaseconjuntista que descreva o funcionamento da teoria quântica não-relativista, e discutimos algumas vantagens dessa estruturação perante uma baseada na teoria de conjuntos clássica.

Palavras-chave: Mecânica quântica; identidade; individualidade; teoria de quase-conjuntos; estruturas matemáticas.

\section{Notas}

${ }^{1}$ Sobre isso, ver Pessoa 2003, 2006.

2 Sobre alguns 'paradoxos relativísticos', pode-se consultar Malin 2001 cap.2.

${ }^{3}$ Aqui ficaremos restrito à chamada "mecânica quântica não relativista" (também chamada de mecânica quântica ortodoxa).

4 Toraldo di Francia diria que as propriedades dos objetos quânticos são nomológicas, ou seja, dadas por leis físicas, e portanto invariantes para cada tipo de objeto 1981 p.222.

${ }^{5}$ São exemplos de bósons os fótons, os glúons, o bóson de Higgs, algumas partículas compostas (tais como os mésons) e alguns núcleos atômicos estáveis como o hélio-4.

${ }^{6}$ Uma discussão completa sobre isso pode ser encontrada em French \& Krause 2006 cap.3 e 4.

${ }^{7}$ Em geral, as noções de função, derivada, integral etc. podem ser expressas em termos conjuntistas.

${ }^{8}$ O artigo principal de Bell (Bell 1987) foi publicado em 1964, e uma discussão muito abrangente se encontra em Bell 1987 e em Wick 1996 cap.8. Para uma prova simples do teorema de Kochen-Specker, veja Bitbol 1996 Anexo 3. Para uma análise geral de tais teoremas e dos problemas deles advindos, veja Pessoa 2003, 2006.

${ }_{9}^{9}$ Russell, durante algum tempo, partilhou dessa posição: veja Russell 1978, segunda parte.

${ }^{10}$ Em linguagem de segunda ordem, podemos escrever tal princípio assim: $\forall F(F(x) \leftrightarrow$ $F(y)) \rightarrow x=y$.

Principia 17(1): 103-135 (2013). 
${ }^{11}$ Para mais detalhes, veja Teller 1995.

12 Um exemplo ilustra bem essa diferença: massa é uma propriedade intrínseca da matéria (todo corpo tem massa), mas o peso já não é pois depende do campo gravitacional no qual esta matéria se encontra.

${ }^{13}$ Entre outras, uma das conclusões do artigo de Black é que tal exemplo mostra que o PII não é um princípio necessariamente válido. Dada tal possibilidade, os filósofos passaram a restringir as propriedades ao alcance do quantificador universal $\forall F$, obtendo assim formas distintas do PII. Não obstante, isto é problemático, pois a restrição a algumas propriedades altera o princípio, que já não fala de todas as propriedades, mas de algumas. Não adentraremos agora na discussão sobre os méritos desse exemplo bastante discutido na literatura.

${ }^{14}$ Por exemplo, podemos pensar que não conseguimos observar um objeto microscópico como um vírus ou uma bactéria o tempo inteiro, ou um macroscópico como um grão de areia sendo levado pelo mar em uma praia, mas no contexto clássico isto é assumido como uma incapacidade epistemológica nossa.

${ }^{15}$ Dito de outra forma, usando a matemática clássica o fato da permutação de objetos não levar a um arranjo diferente somente ocorre se estivermos tratando do mesmo objeto. Mas as partículas do caso 7') acima não são o mesmo objeto: elas são apenas indistinguíveis! Assim, o truque é iniciar com objetos discernidos pelos seus rótulos (ou nomes, se preferirmos) já que devido à linguagem e à matemática clássica não temos escapatória, e então posteriormente assumir que somente certos estados contam: os invariantes por permutação, que são exatamente àqueles que são consoantes com a indiscernibilidade.

16 Citado em Krause 2003.

${ }^{17}$ Não adentraremos mais à questão de uma possível individualidade transcendental para tais partículas devido ao que falamos rapidamente acima, a saber, de que tudo leva a crer que algum tipo de substrato metafísico realmente não é possível de ser admitido para os objetos quânticos, ou se admitido, que tal "variável oculta" tem de ser não-local (não satisfazendo assim o postulado da teoria da relatividade que afirma que nada pode viajar mais rápido que a luz), ou então que a $M Q$ se torne contextual (isto é, que seus resultados sejam 'dependentes' do aparelho e das condições de medida que agem sobre o objeto, o que é muito estranho e afeta completamente a objetividade científica: para citar um exemplo, grosso modo é como se o resultado de uma medição fosse diferente se usássemos uma fita métrica ou se usássemos um paquímetro). Dada tais 'condições', a assunção de variáveis ocultas parece estar descartada: realmente, tudo o que temos parece ser o que a teoria nos mostra. Além disso, um outro problema dessa teoria transcendental é o da 'describabilidade': se para lograrmos êxito na descrição do objeto em sua forma mais primária necessitamos ter uma lista de atributos, como podemos descrever aqueles que transcendem estes atributos? Para mais detalhes sobre esta discussão, o leitor pode consultar French \& Krause 2006.

18 Como diz Reichenbach 1944, p.38 e p.255ss, os objetos da física clássica teriam uma "genidentity", a qual seria basicamente a relação que conecta diferentes estados de uma mesma coisa em diferentes tempos. De acordo com este autor, é sobre as propriedades dessa relação (a saber, continuidade, impenetrabilidade e a possibilidade de rotulagem) que se baseia a noção de identidade de objetos físicos do nosso mundo macroscópico.

${ }^{19} \mathrm{Na} \mathrm{MQ}$, existem várias outras situações nas quais não é possível distinguir entre dois caminhos possíveis de uma partícula, e há autores que sustentam, inclusive, que na escala microscópica os próprios conceitos de espaço e de tempo necessitam qualificação. Por exem-

Principia 17(1): 103-135 (2013). 
plo, Max Jammer (2010, p.290) afirma claramente que "o resultado obtido por Salecker e Wigner com respeito às limitações que cercam as medidas de intervalos espaço-temporais na mecânica quântica, [...] priva as noções tradicionais de espaço e tempo de qualquer significado operacional na microfísica".

${ }^{20} \mathrm{O}$ que em lógica seria a irreflexibilidade da identidade.

${ }^{21}$ Zermelo-Fraenkel com axioma da escolha (se assumirmos no formalismo átomos - que não são conjuntos, mas podem ser elementos de conjuntos - temos a teoria ZFCU, com "U" de Urelemente). A teoria de conjuntos de ZFC é a mais preferida e usada pelos filósofos e matemáticos em geral, embora a matemática também possa ser fundamentada em uma teoria de categorias, por exemplo, ou mesmo em lógicas de ordem superior.

${ }^{22}$ Citamos aqui apenas alguns trabalhos mais relevantes do autor sobre o tema. Outras indicações podem ser consultadas nas bibliografias indicadas nessas obras.

${ }^{23} \mathrm{Na}$ exposição que virá em sequência ficaremos restritos (e seguiremos de perto) principalmente a obra de French \& Krause 2006, cap.7, onde é mostrada uma condensação dos principais resultados de tal arcabouço. Outrossim, no presente artigo, não apresentaremos todos os axiomas e definições da teoria de quase conjuntos, mas sim apenas alguns mais importantes (como dito, na bibliografia citada podem ser encontrado mais esclarecimentos sobre o tema, bem como outros resultados que não apresentaremos aqui).

${ }^{24}$ Este último axioma é interessante da perspectiva da física pois sugere que os $M$-átomos podem ser compostos de $m$-átomos de algum modo.

${ }^{25}$ Obviamente isto é importante, pois dada suas aplicações também queremos conservar os resultados e teorias da matemática clássica.

${ }^{26}$ É também nesse sentido que na teoria clássica de conjuntos, tomada a partir da Lei de Leibniz, os elementos de um conjunto são de certo modo 'indivíduos' bem definidos: como podemos sempre tomar a classe unitária de um elemento (que é a classe a qual só ele pertence), podemos sempre ter um indivíduo bem estabelecido ao identificá-lo com esta classe. ${ }^{27}$ Uma classe unitária forte em $\mathfrak{Q}$ é um qset que tem quase-cardinal igual a 1.

${ }^{28} \mathrm{O}$ Axioma da Extensionalidade em ZF é definido da seguinte forma: $\forall x \forall y(\forall z(z \in x \leftrightarrow$ $z \in y) \rightarrow x=y$ ). Intuitivamente, tal axioma expressa a ideia de que para quaisquer conjuntos $x$ e $y$, se todos os elementos do conjunto $x$ são elementos do conjunto $y$ e reciprocamente, então $x$ e $y$ são o mesmo (um só) conjunto.

${ }^{29}$ Sobre esse ponto, veja French \& Krause 2006 p.327ss.

${ }^{30}$ Como também já ressaltamos, outros axiomas, teoremas e resultados sobre a teoria $\mathfrak{Q}$ podem ser encontrados em French \& Krause 2006 cap.7.

${ }^{31}$ Sobre esse ponto, veja por exemplo da Costa \& French 2003.

32 Normalmente, uma estrutura é expressa como $\mathfrak{U}=\left\langle D, R_{i}\right\rangle_{i \in I}$.

33 Por exemplo, uma estrutura para representar a mecânica clássica de partículas pode ser vista em Suppes 1957 cap.12, e uma para a teoria sintética da evolução da biologia pode ser encontrada em Magalhães \& Krause 2001.

${ }^{34} \mathrm{O}$ tempo, aqui, é tomado como um parâmetro externo.

${ }^{35}$ Em seminário dado no Núcleo de Lógica e Fundamentos da Ciência da UFSC, em 07/07/2013.

${ }^{36}$ Por exemplo, é sabido que tal axiomática não permite tratar do choque entre partículas, de energias muito grandes, ou mesmo tratar dos quarks, léptons e dos núcleos dos átomos, casos em que devemos usar a mecânica quântica de campos (também chamada de mecânica

Principia 17(1): 103-135 (2013). 
quântica relativista). Não obstante, para tratar da aniquilação e criação de partículas, basta ampliar a estrutura acima incluindo mais um axioma sobre espaços de Fock.

${ }^{37}$ Frase proferida em seminário dado na UFSC em 27/09/2010. Há, inclusive, tentativas de erigir a MQ como que 'englobando' na própria teoria um conjunto de linguagens experimentais (veja por exemplo Bitbol 1996, 2001, Destouches 1948, 1960, Heelan 1970).

${ }^{38}$ Aqui faremos somente uma discussão geral sobre tal conceito, apenas para enfatizar mais esta diferença existente na teoria de quase-conjuntos frente às teorias clássicas.

${ }^{39}$ Dito de outra forma, podemos afirmar que nesta estrutura $b=-b$ porque $b$ e $-b$ são indistinguíveis com os recursos da estrutura: no caso, os automorfismos existentes.

${ }^{40}$ Para o exemplo dado no texto, um dos modos de fazermos isso é acrescentar à estrutura original novas relações (no caso, unárias) que consistem de todos os subconjuntos unitários dos elementos de $\mathbb{Z}$ (que logicamente correspondem à propriedade "ser idêntico a si mesmo"). Deste modo, obtemos $\mathfrak{Z}^{\prime}=\langle\mathbb{Z},+,\{0\},\{1\},\{-1\}, \ldots\rangle$, que como facilmente se vê é rígida: diferentemente de antes, a função $f$ agora não leva mais ao oposto de um elemento, mas sim somente ao próprio elemento, constituindo-se (tal automorfismo) na própria função identidade.

${ }^{41}$ Interessante notar, todavia, que a não possibilidade de rigidificação das estruturas quaseconjuntistas não advém apenas da falta de identidade para os objetos do domínio da estrutura (como normalmente se apregoa), mas sim principalmente devido à impossibilidade de ordenação de tais objetos: este é um resultado muito interessante e que destoa da visão usual. Na verdade, a questão da falta de identidade para os $m$-átomos dos qsets é em particular importante para o fato de não podermos ter automorfismos nas quase-estruturas, mas com relação à questão da rigidificação em especial, a impossibilidade de tal intento se dá principalmente por não podermos ter a ordenação de tais $m$-átomos, como dito.

Principia 17(1): 103-135 (2013). 